\title{
Validamycin A Induces Broad-Spectrum Resistance Involving Salicylic Acid and Jasmonic Acid/Ethylene Signaling Pathways
}

\author{
Chuanhong Bian, Yabing Duan, Jueyu Wang, Qian Xiu, Jianxin Wang, Yiping Hou, Xiushi Song, and \\ Mingguo Zhou ${ }^{\dagger}$
}

College of Plant Protection, Nanjing Agricultural University, Nanjing 210095, China

Accepted 18 August 2020.

\begin{abstract}
Validamycin A (VMA) is an aminoglycoside antibiotic used to control rice sheath blight. Although it has been reported that VMA can induce the plant defense responses, the mechanism remains poorly understood. Here, we found that reactive oxygen species (ROS) bursts and callose deposition in Arabidopsis thaliana, rice (Oryza sativa L.), and wheat (Triticum aestivum L.) were induced by VMA and were most intense with $10 \mu \mathrm{g}$ of VMA per milliliter at $24 \mathrm{~h}$. Moreover, we showed that VMA induced resistance against Pseudomonas syringae, Botrytis cinerea, and Fusarium graminearum in Arabidopsis leaves, indicating that VMA induces broad-spectrum disease resistance in both dicots and monocots. In addition, VMA-mediated resistance against $P$. syringae was not induced in $N a h G$ transgenic plants, was partially decreased in nprl mutants, and VMA-mediated resistance to $B$. cinerea was not induced in npr1, jarl, and ein2 mutants. These results strongly indicated that VMA triggers plant defense responses to both biotrophic and necrotrophic pathogens involved in salicylic acid (SA) and jasmonic acid/ethylene (JA/ET) signaling pathways and is dependent on NPR1. In addition, transcriptome analysis further revealed that VMA regulated the expression of genes involved in SA, JA/ET, abscisic acid (ABA), and auxin signal pathways. Taken together, VMA induces systemic resistance involving in SA and JA/ET signaling pathways and also exerts a positive influence on $\mathrm{ABA}$ and auxin signaling pathways. Our study highlights the creative application of VMA in triggering plant defense responses against plant pathogens, providing a valuable insight into applying VMA to enhance plant resistance and reduce the use of chemical pesticides.
\end{abstract}

Keywords: abscisic acid, Arabidopsis thaliana, auxin, callose deposition, plant defense responses, reactive oxygen species, salicylic acid, validamycin A

The sequence reads of RNA-Seq data have been deposited in the National Center for Biotechnology Information Sequence Read Archive under accession numbers SRR10256658 to SRR10256667 as part of BioProject PRJNA565687.

${ }^{\dagger}$ Corresponding author: M. Zhou; mgzhou@njau.edu.cn

Funding: This research was supported by the key program of National Natural Science Foundation of China (31730072) and the general program of National Natural Science Foundation of China (31772190).

*The $\boldsymbol{e}$-Xtra logo stands for "electronic extra" and indicates there are supplementary materials published online.

The author(s) declare no conflict of interest.

(c) (1) $\circledast \Theta$ Copyright $(02020$ The Author(s). This is an open access article distributed under the CC BY-NC-ND 4.0 International license.
Validamycin A (VMA), which was named jinggangmycin A in China, isolated from Streptomyces hygroscopicus (Jensen) Waksman and Henrici var. limoneus by Iwasa et al. (1970) and from S. hygroscopicus var. jinggangensis by Shanghai Pesticide Research Institute (Shen 1981). VMA is an aminoglycoside compound, its sugar moiety (a glucose residue) lacks an amino group, and the compound is thought to be easily hydrolyzed to bioactive validoxylamine A (VAA) by glycosidases (Ishikawa et al. 2005; Trinci 1985).

VMA has been mainly used to control rice sheath blight caused by Rhizoctonia solani for nearly half century because it was originally found only causing the abnormal branches of the heading hyphae of Rhizoctonia species (Iwasa et al. 1970) and could not inhibit growth of any plant fungal pathogens in vitro. The selectivity mode of action of VMA was respectively reported to inhibit energy metabolism and change the cell-wall component by suppressing trehalase activity in Rhizoctonia fungi (Kido et al. 1986; Robson et al. 1989a and b; Shigemoto et al. 1989, 1992). However, our research group recently found that VMA could decrease the deoxynivalenol (DON) toxin biosynthesis in Fusarium graminearum by inhibiting trehalase and increase wheat resistance by upregulating expression of pathogenesis-related genes, and VMA was invented to control Fusarium head blight on wheat synergistically with ergosterol biosynthesis inhibitors ( $\mathrm{Li}$ et al. 2019; Zhou et al. 2018). In addition, VMA was reported to efficiently control tomato Fusarium wilt, late blight, powdery mildew, and cabbage black rot in the field trials (Ishikawa et al. 2004, 2005). Some studies presumed that VMA might induce plant defense responses through enhancing the activity of defense-related enzymes in plants (Zhang et al. 2001; Ishikawa et al. 2005, Li et al. 2019). But a puzzling question remains. How does VMA induce plant defense responses?

In this study, we used different mutant plants of Arabidopsis thaliana to reveal the pathway of VMA inducing defense responses against infection of Pseudomonas syringae, $F$. graminearum, and Botrytis cinerea, and also checked the VMA-induced defense in rice (Oryza sativa L.) and wheat (Triticum aestivum L.). We found that VMA induces systemic resistance via the salicylic acid (SA) and jasmonic acid/ethylene (JA/ET) signaling pathways and exerts a positive influence on abscisic acid (ABA) and auxin signaling pathways in Arabidopsis. It also induces resistance in rice and wheat. Plant disease can cause serious crop yield and quality damage. The plant immune activator is often considered as a powerful and environmentally friendly tool to control crop diseases. The plant immune elicitor properties of VMA provide a valuable insight for controlling broad-spectrum crop diseases. Our work is the first to 
illuminate the mechanism of VMA triggering defense response and highlights an innovative application of VMA in plant disease control.

\section{RESULTS}

Effects of VMA against $P$. syringae, $F$. graminearum, and B. cinerea in vitro.

Our previous work demonstrated that VMA can induce host resistance in wheat and decrease the mycotoxins in grains produced by $F$. graminearum ( $\mathrm{Li}$ et al. 2019). To evaluate the effectiveness of VMA in improving plant resistance against different pathogens, the effects of VMA against $P$. syringae pv. tomato DC3000 (DC3000), F. graminearum (PH-1) and $B$. cinerea (B05.10) were determined in vitro. VMA did not affect bacterial growth and extracellular polysaccharide production of $P$. syringae (Fig. 1A and B). Although VMA inhibited the mycelial growth of $F$. graminearum and $B$. cinerea at a concentration of $100 \mu \mathrm{g} \mathrm{ml}^{-1}$, the inhibition rate was only 18.5 and $15.2 \%$, respectively (Fig. 1C to E). These data indicated that the inhibitory effect of VMA against these pathogens was not promising in vitro.
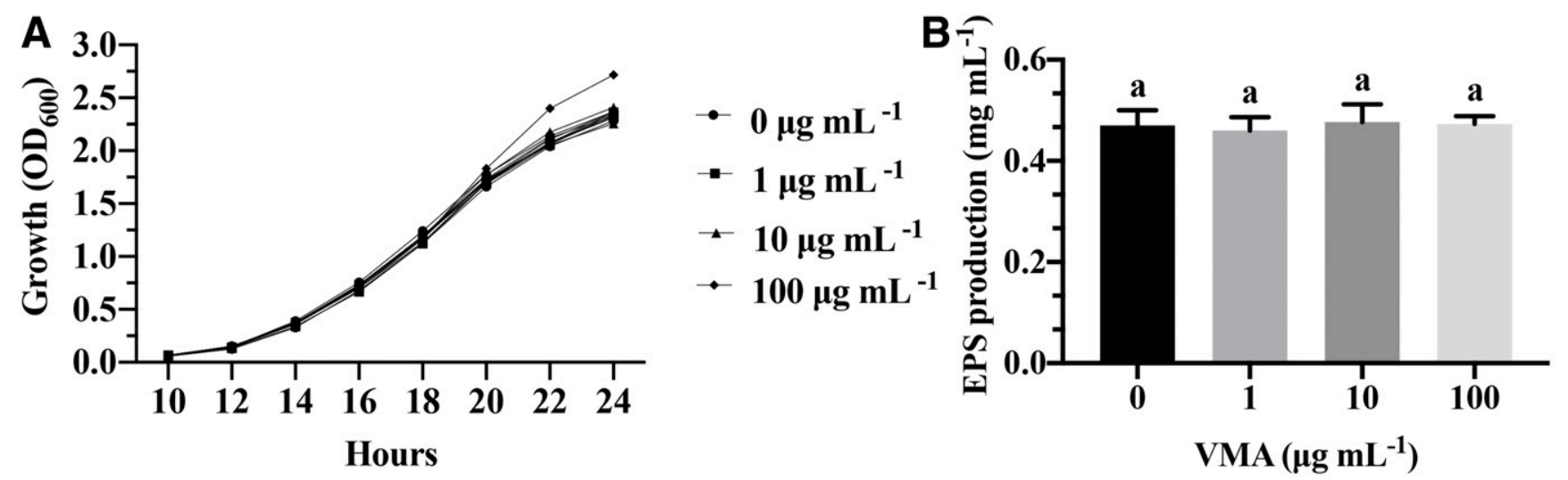

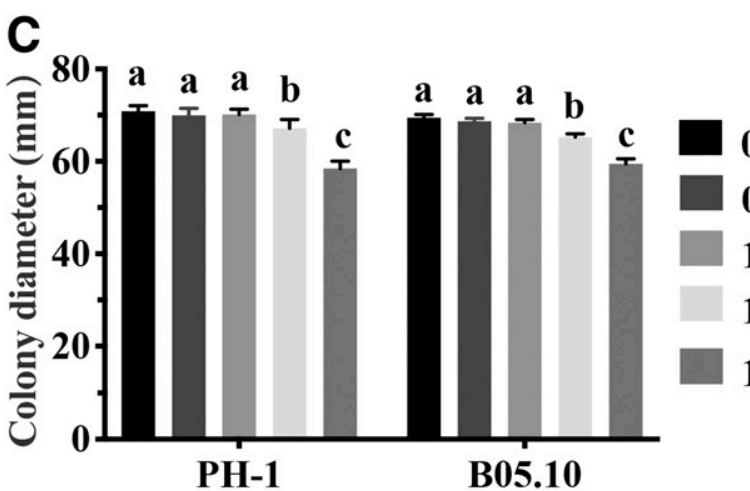

Strain

$\mathbf{E}$
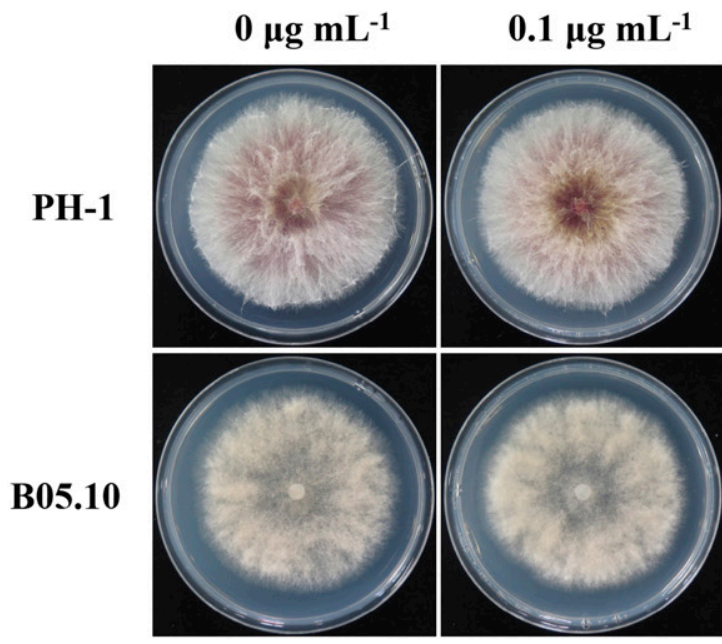

$0 \mu \mathrm{g} \mathrm{mL}^{-1}$

$0.1 \mu \mathrm{g} \mathrm{mL} \mathrm{L}^{-1}$

$1 \mu \mathrm{g} \mathrm{mL}^{-1}$

$10 \mu \mathrm{g} \mathrm{mL}^{-1}$

$100 \mu \mathrm{g} \mathrm{mL}^{-1}$
D

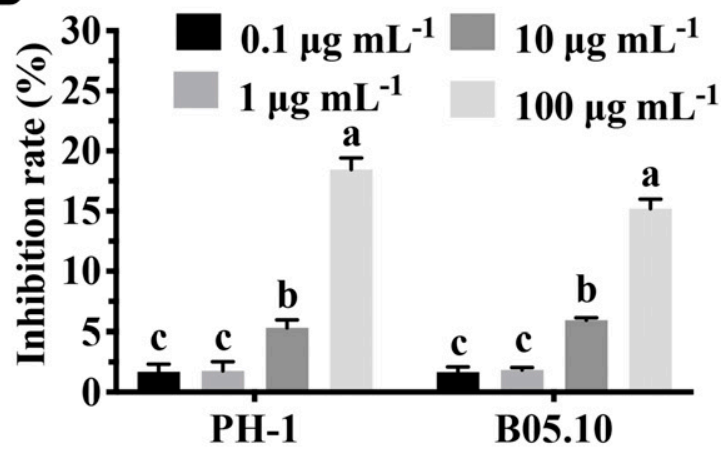

Strain
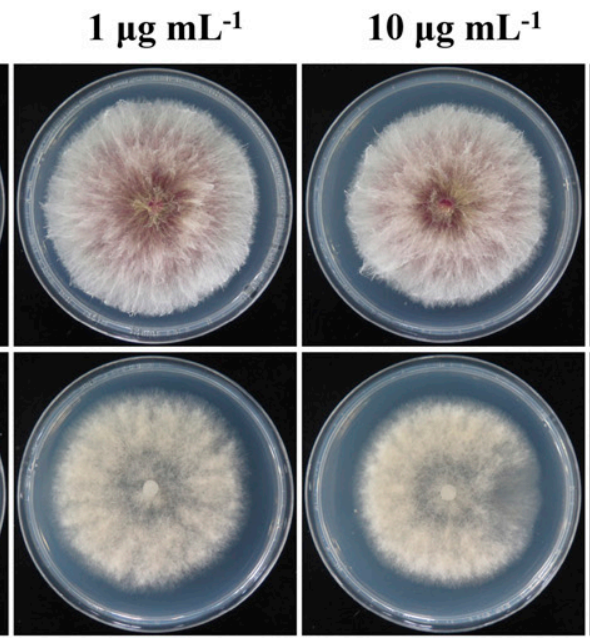

$100 \mu \mathrm{g} \mathrm{mL} \mathrm{L}^{-1}$

Fig. 1. Control effects of validamycin A (VMA) on Pseudomonas syringae, Fusarium graminearum, and Botrytis cinerea in vitro. A, The optical density at 600 $\mathrm{nm}\left(\mathrm{OD}_{600}\right)$ of Pseudomonas syringae pv. tomato DC3000 (DC3000) was detected every $2 \mathrm{~h}$ in King's B liquid medium after VMA (0.1, 1,10 , and $100 \mu \mathrm{g} \mathrm{ml}^{-1}$ ) and sterile distilled $\mathrm{H}_{2} \mathrm{O}$ were added. B, Extracellular polysaccharide production of DC3000 after adding VMA $\left(0.1,1,10\right.$, and $100 \mu \mathrm{g}$ ml $\left.{ }^{-1}\right)$ and sterile distilled $\mathrm{H}_{2}$ O. C, Colony diameter of $\mathrm{PH}-1$ and $\mathrm{B} 05.10$ on potato dextrose agar plates containing VMA $\left(0.1,1,10\right.$, and $\left.100 \mu \mathrm{g} \mathrm{ml}^{-1}\right)$ and sterile distilled $\mathrm{H}_{2} \mathrm{O}$. D, Inhibition rate of VMA against PH-1 and B05.10. E, Colony morphology of PH-1 and B05.10 on PDA plates containing VMA. Statistical analysis was performed using one-way analysis of variance, followed by the Tukey multiple comparison test. The level of significance was set at $P<0.05$. The statistics and bar graphs were performed using a GraphPad Prism 8.2 (Graph Pad Software, La Jolla, CA, U.S.A.). 
VMA can inhibit in vivo disease development caused by $P$. syringae, $F$. graminearum, and $B$. cinerea.

The in vivo control efficacy of VMA against $P$. syringae, $F$. graminearum, and B. cinerea were determined in Arabidopsis. Arabidopsis leaves were pretreated with VMA prior to inoculation with $P$. syringae. Typical disease symptoms of watersoaked spots, yellow leaves, and severe necrosis were observed in the VMA treatments and control groups after inoculation for 1 , 3, and 7 days, respectively (Fig. 2A and B; Supplementary Fig. S1). Compared with the control groups, all the VMA treatments significantly reduced the disease symptoms of mild yellow leaves and necrosis (Fig. 2A; Supplementary Fig. S1). The control efficacy increased with increasing VMA doses (Fig. 2B; Supplementary Fig. S1). Surprisingly, at a concentration of $100 \mu \mathrm{g} \mathrm{ml}^{-1}$, VMA exhibited lower in vivo control efficacy in comparison with VMA at $10 \mu \mathrm{g} \mathrm{ml}^{-1}$ and had a similar control efficacy with VMA at $1 \mu \mathrm{g} \mathrm{ml}^{-1}$. Bacterial biomass in infected leaves with VMA at $100 \mu \mathrm{g} \mathrm{ml}^{-1}$ was higher compared than that in leaves with a VMA concentration of $10 \mu \mathrm{g} \mathrm{ml}{ }^{-1}$, further confirming that the control efficacy of VMA at $10 \mu \mathrm{g} \mathrm{ml}^{-1}$ was better (Fig. 2C). In addition, the in vivo control efficacy of VMA against $F$. graminearum and $B$. cinerea in Arabidopsis were also determined. Compared with the no-VMA treatments, VMA exhibited a significant reduction of diseased lesions at the different concentrations (Fig. 3A and B). Among the VMA treatments, VMA treatment at $10 \mu \mathrm{g} \mathrm{ml}^{-1}$ exhibited the best control efficacy against either $F$. graminearum or $B$. cinerea, consistent with the above-described findings from the in vivo test with $P$. syringae. In the $10 \mu \mathrm{g} \mathrm{ml}^{-1}$ treatment, VMA had approximately 40 and $55 \%$ control efficacy against $F$. graminearum and B. cinerea in Arabidopsis, respectively (Fig. 3C). This is consistent with the results that fungal biomass was significantly reduced in the infected leaves treated with VMA at $10 \mu \mathrm{g} \mathrm{ml}^{-1}$ (Fig. 3D and E). The results indicated that VMA was more effective for controlling plant pathogens in vivo than in vitro. Thus, we concluded that VMA can induce plant defense response, thereby improving host resistance against plant pathogens.
A

1 dpi
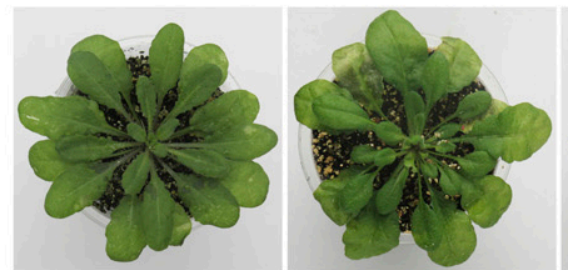

3 dpi
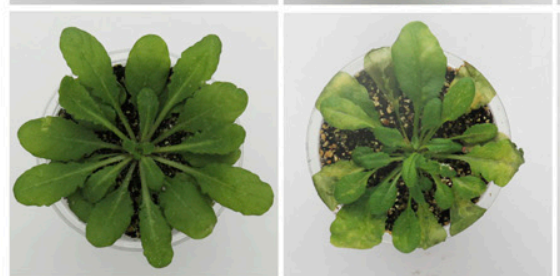

7 dpi
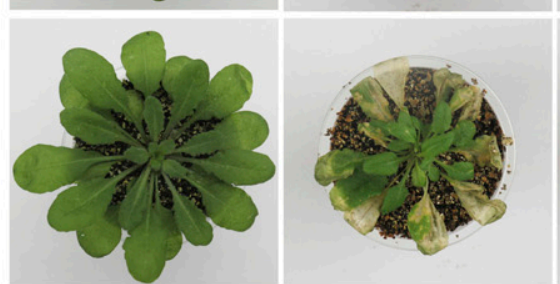

B

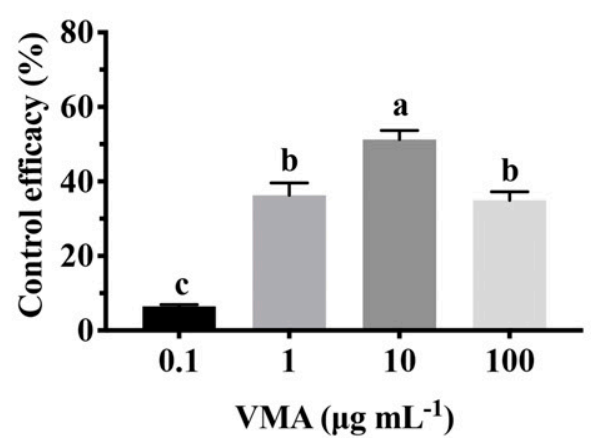

$0.1 \mu \mathrm{g} \mathrm{mL}^{-1}$
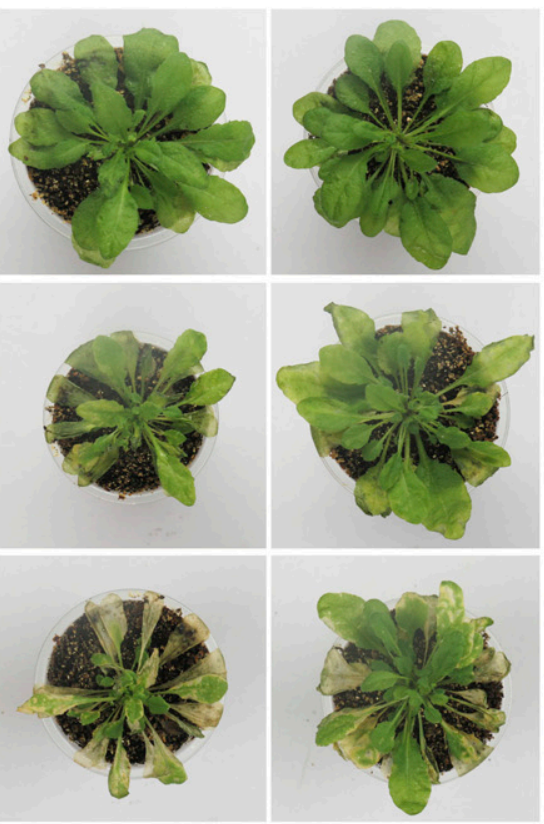

$10 \mu \mathrm{g} \mathrm{mL}^{-1}$
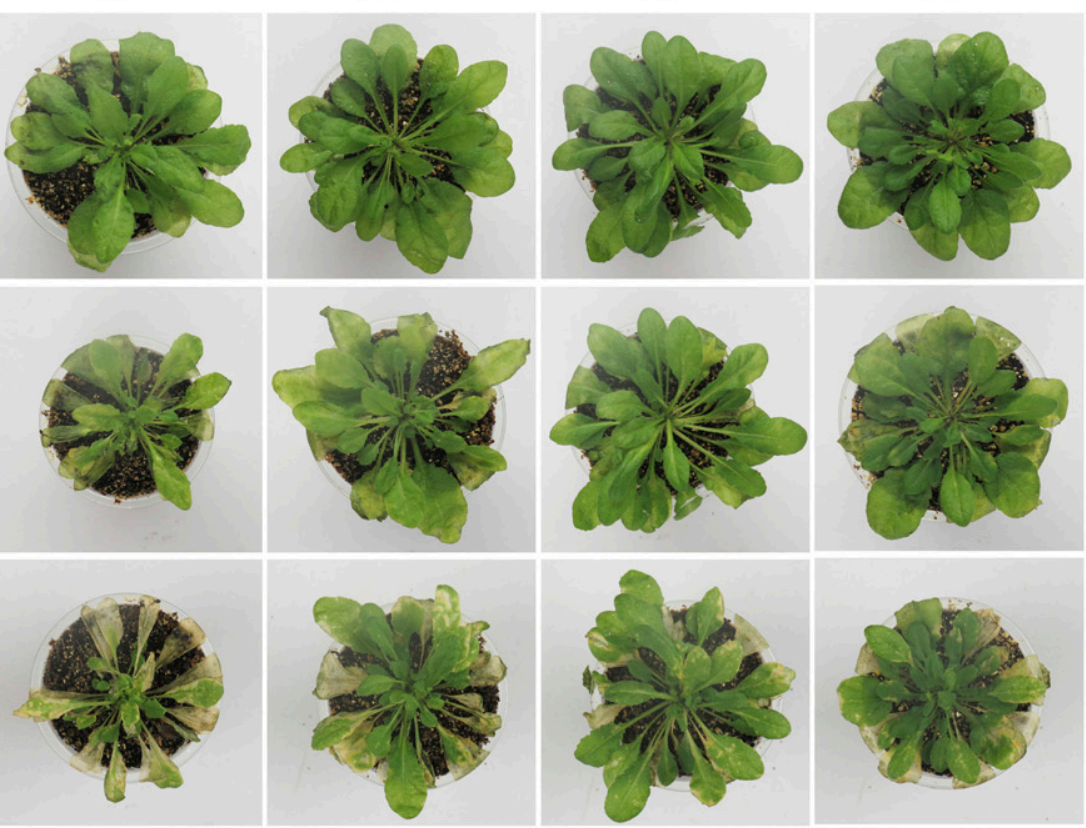

C

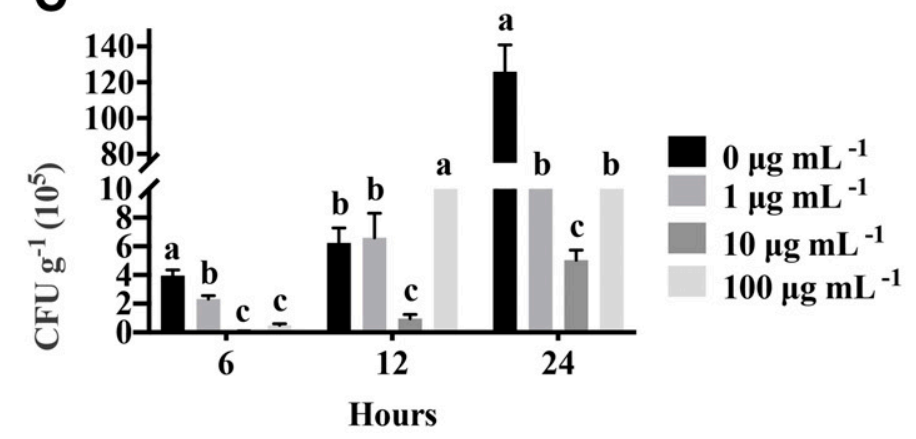

Fig. 2. Control efficacy of validamycin A (VMA) on Pseudomonas syringae in vivo. A, Disease symptoms of spray-inoculated plants pretreated with VMA and P. syringae pv. tomato DC3000 (DC3000) at 1,3, and 7 days postinoculation (dpi). B, Control efficacy of VMA against DC3000 after inoculation for 7 days. C, The biological biomass of DC3000 in spray-inoculated plants pretreated with VMA and DC3000 at 6, 12, and 24 h. Arabidopsis plants were pretreated with VMA $\left(0.1,1,10\right.$, and $\left.100 \mu \mathrm{g} \mathrm{ml}^{-1}\right)$ and sterile distilled $\mathrm{H}_{2} \mathrm{O}$ for $24 \mathrm{~h}$ and were spray-inoculated with DC 3000 suspensions $\left(1 \times 10^{8} \mathrm{CFU} \mathrm{m}^{-1}\right)$ or sterile doubledistilled $\mathrm{H}_{2} \mathrm{O}$ (Mock). Disease symptoms were observed after inoculation for 1, 3, and 7 days. Control efficacy were evaluated at 7 dpi. The bacterial biomass was determined using the method of plate dilution at 6,12 , and $24 \mathrm{~h}$ after inoculation. These experiments were repeated three times with similar results. Statistical analysis was performed using one-way analysis of variance, followed by the Tukey multiple comparison test. The level of significance was set at $P<$ 0.05. The statistics and bar graphs were performed using a GraphPad Prism 8.2 (Graph Pad Software, La Jolla CA, U.S.A.). 
Induction of reactive oxygen species (ROS) and callose deposition in Arabidopsis, rice, and wheat by VMA.

To investigate the mechanism of VMA triggering plant defense response, ROS bursts and callose deposition were examined in plants. ROS bursts were detectable in Arabidopsis leaves after treatment with VMA at 12 and $24 \mathrm{~h}$, and it was noted that ROS bursts were most intense when treated with $10 \mu \mathrm{g}$ of VMA per milliliter for $12 \mathrm{~h}$ (Fig. 4A). The accumulation of hydrogen peroxide $\left(\mathrm{H}_{2} \mathrm{O}_{2}\right)$ was also measured, and the results further proved that a VMA concentration of $10 \mu \mathrm{g} \mathrm{ml}^{-1}$ was more effective than other treatments (Fig. 4B). Similar to ROS bursts, callose deposition was also detected at 12 and $24 \mathrm{~h}$ after VMA treatment. In addition, callose deposition was noticeably enhanced under the condition of treatment with VMA at $10 \mu \mathrm{g} \mathrm{ml}^{-1}$ at $24 \mathrm{~h}$ (Fig. 4A and C). Furthermore, the dynamics of ROS bursts and callose deposition were examined in Arabidopsis leaves treated with VMA at $10 \mu \mathrm{g} \mathrm{ml}^{-1}$. When Arabidopsis leaves were treated with VMA at $10 \mu \mathrm{g} \mathrm{ml}^{-1}$ for 6 , $12,24,36$, and $48 \mathrm{~h}$, ROS bursts were observed at $6 \mathrm{~h}$, increased significantly at 12 and $24 \mathrm{~h}$, and weakened gradually at 36 and $48 \mathrm{~h}$ (Supplementary Fig. S2A). The results from $\mathrm{H}_{2} \mathrm{O}_{2}$ production tests are in agreement with ROS bursts (Supplementary Fig. S2B), demonstrating that VMA indeed induced $\mathrm{H}_{2} \mathrm{O}_{2}$ accumulation, triggering ROS bursts, especially with VMA treatment at concentrations of $10 \mu \mathrm{g} \mathrm{ml}^{-1}$ for 12 and $24 \mathrm{~h}$. Under VMA treatment at $10 \mu \mathrm{g} \mathrm{ml}^{-1}$, callose deposition gradually increased from 6 to $24 \mathrm{~h}$ and, then, gradually decreased from 24 to $48 \mathrm{~h}$ (Supplementary Fig. S2A and C). These results indicated that plants can deploy a potentiated defense response after treatment with $10 \mu \mathrm{g}$ of VMA per milliliter for $24 \mathrm{~h}$.

In order to determine whether VMA can induce defense responses in other plants, ROS bursts and callose deposition were detected in wheat or rice under treatments of 1,10 , and $100 \mu \mathrm{g}$ of VMA per milliliter for 12 and $24 \mathrm{~h}$, respectively. In rice leaves, VMA at $10 \mu \mathrm{g} \mathrm{ml}^{-1}$ significantly enhanced ROS bursts and callose deposition in comparison with other treatments and control groups (Fig. 5). Moreover, the same phenomenon that VMA significantly induced plant defense response at the
A

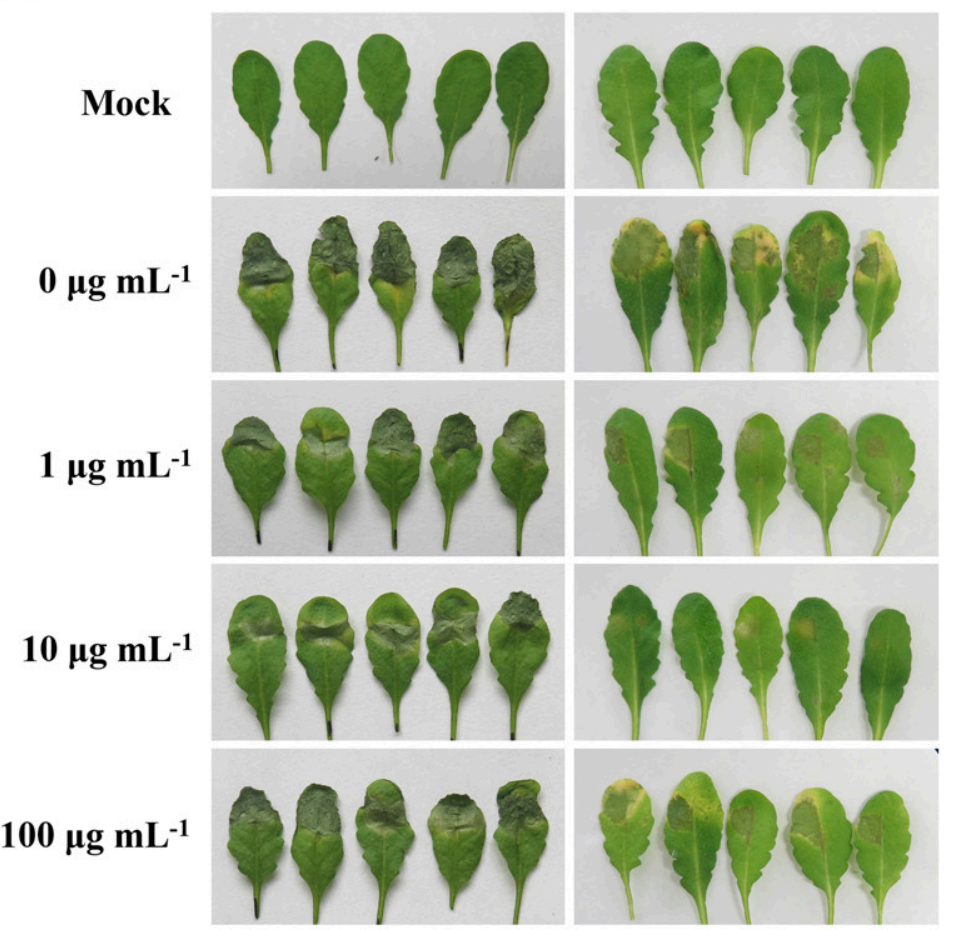

D

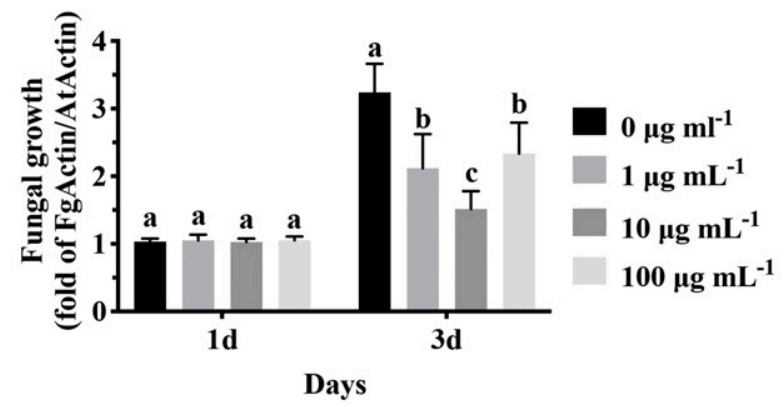

B
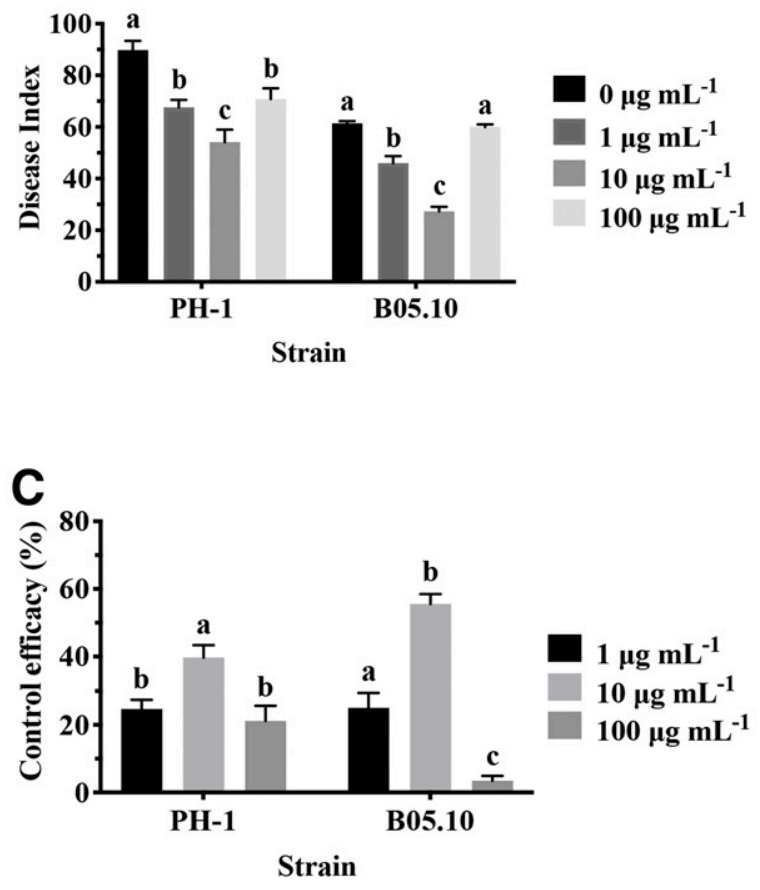

$\mathbf{E}$

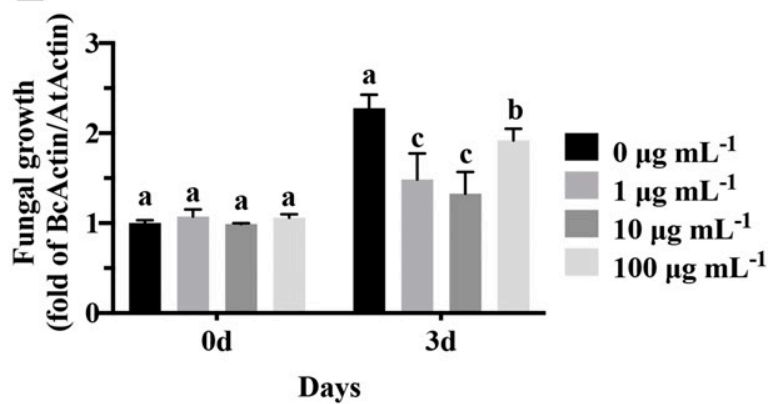

Fig. 3. Control efficacy of validamycin A (VMA) on Fusarium graminearum and Botrytis cinerea in vivo. A, Disease symptoms of plants pretreated with VMA and then inoculated with PH-1 and B05.10 for 5 days. B and C, Disease index and control efficacy, respectively, of VMA on PH-1 and B05.10. D and E, The biomass of PH-1 and B05.10 in infected plants, respectively. The plants were pressure-infiltrated with small mycelia fragments of PH-1 and drop-inoculated with B05.10 spores suspension $\left(1 \times 10^{6}\right.$ spores $\left.\mathrm{ml}^{-1}\right)$. The relative biomass of fungi in infected plants was measured by the ratio of FgActin/AtActin 2 and BcActin/AtActin2, respectively. These experiments were repeated three times with similar results. Statistical analysis was performed using one-way analysis of variance, followed by the Tukey multiple comparison test. The level of significance was set at $P<0.05$. The statistics and bar graphs were performed using a GraphPad Prism 8.2 (Graph Pad Software, La Jolla, CA, U.S.A.). 
concentration of $10 \mu \mathrm{g} \mathrm{ml}^{-1}$ was observed in the leaf sheath and coleoptiles of rice (Supplementary Figs. S3 and S4). Similarly, significantly enhanced ROS bursts and callose deposition as affected by VMA at $10 \mu \mathrm{g} \mathrm{ml}^{-1}$ were observed in the leaves and coleoptiles of wheat (Supplementary Figs. S5 and S6). Taken together, VMA can be used as an elicitor for inducing plant defense response, and it exhibited a better effect at $10 \mu \mathrm{g} \mathrm{ml}{ }^{-1}$ for improving plant resistance to pathogens.

\section{VMA enhances ROS bursts and callose deposition} in plants when infected by $\mathrm{DC} 3000$.

The dynamics of ROS bursts and callose deposition were also examined in plants inoculated with DC3000 in the absence or presence of VMA. In the absence of VMA, DC3000 infection slightly induced the accumulation of $\mathrm{H}_{2} \mathrm{O}_{2}$, but did not stimulate callose deposition. The accumulation of $\mathrm{H}_{2} \mathrm{O}_{2}$ increased over time (Fig. 6A to C). In the presence of VMA, DC3000 infection significantly induced both the accumulation of $\mathrm{H}_{2} \mathrm{O}_{2}$ and callose deposition and the extent increased over time (Fig. 6A to $\mathrm{C}$ ). The results indicated that VMA can significantly enhance ROS bursts and callose deposition when the plants are infected by the pathogens.
VMA triggers a defense response to $P$. syringae via the SA signaling pathway that is partly dependent on NPR1 in Arabidopsis.

To elucidate the molecular mechanism responsible for VMA inducing a defense response, defective Arabidopsis plants in different hormone signaling pathways were analyzed. Whether sprayed-inoculated or infiltrated, 5 days later, DC3000 caused visible disease symptoms in the NahG transgenic plants, jarl and nprl mutants, and the wild-type Col-0 plants, indicating that none of the mutant plants exhibited an automatic and effective immune response against DC3000 (Fig. 7). In Arabidopsis plants treated with VMA at $10 \mu \mathrm{g} \mathrm{ml}{ }^{-1}$ prior to inoculation, the disease symptoms had a significant reduction in the wild-type Col-0 and jarl mutants and a slight reduction in $n p r l$ mutants, indicating that the defense response induced by VMA is still functional in these plants (Fig. 7). In contrast, no discernable difference was observed between the controls and VMA treatments in the $N a h G$ transgenic plants, indicating that VMA did not induce defense responses in the NahG transgenic plants (Fig. 7). To further verify the signaling pathways employed by the VMA-mediated defense response,
A

$0 \mu \mathrm{g} \mathrm{mL}$

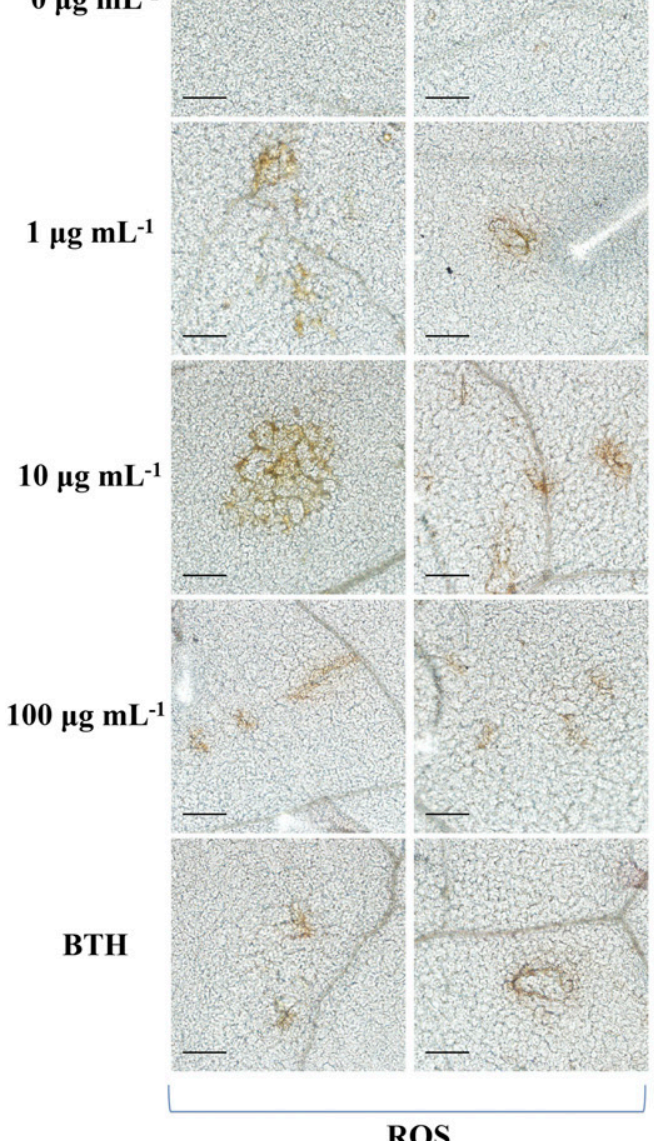

$24 \mathrm{~h}$

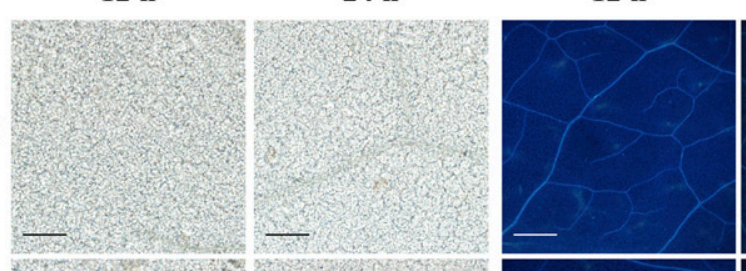

$24 \mathrm{~h}$
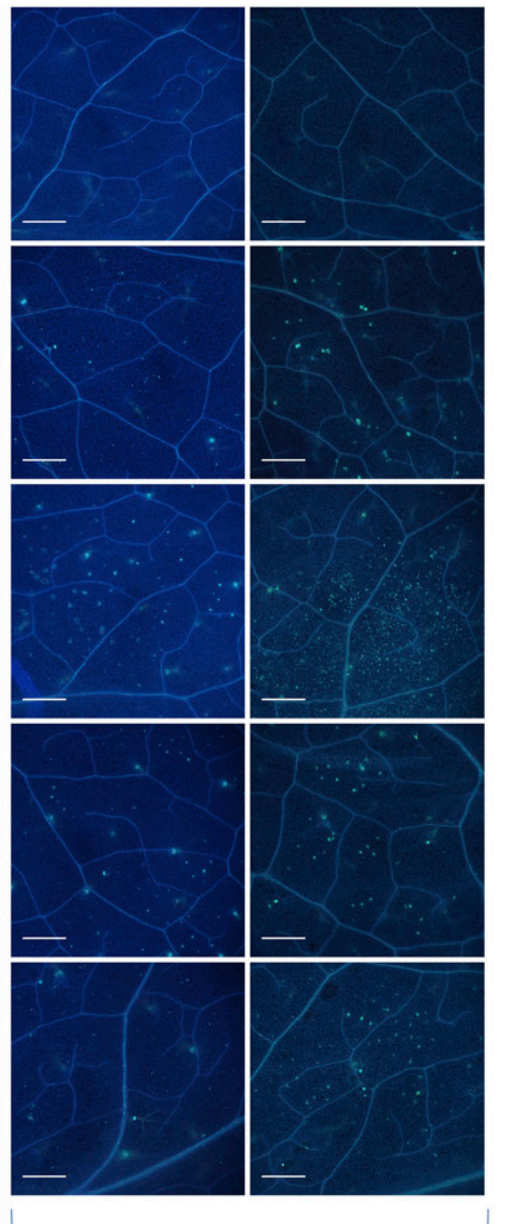

Callose deposition

B

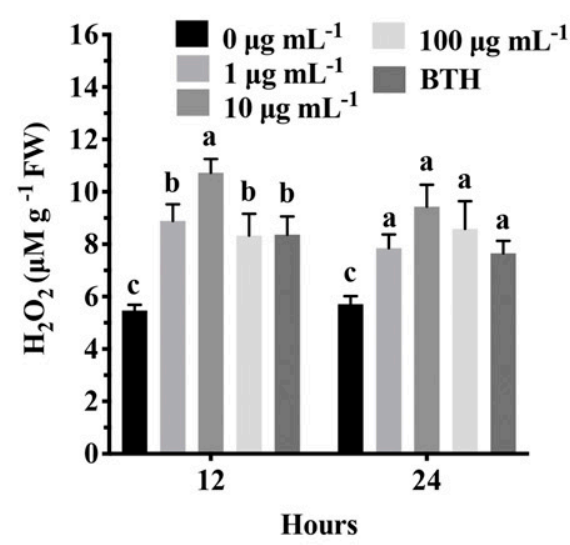

C

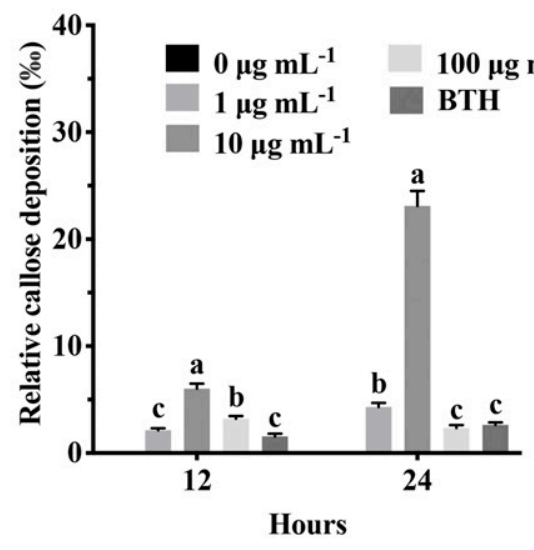

Fig. 4. Reactive oxygen species (ROS) bursts and callose deposition were induced by validamycin A (VMA) in Arabidopsis. A, ROS bursts and callose deposition were visually detected after VMA treatment $\left(1,10\right.$, and $\left.100 \mu \mathrm{g} \mathrm{ml}^{-1}\right)$ for 12 and $24 \mathrm{~h}$, respectively. Benzo $(1,2,3)$ thiadiazole-7-carbothioic acid (BTH) $\left(100 \mu \mathrm{g} \mathrm{ml}^{-1}\right)$ was used as control. ROS bursts were detected by diaminobenzidine tetrachloride staining, and photos were then taken with an Olympus IX-71 inverted fluorescence microscope (Tokyo). Scale bars $=100 \mu \mathrm{m}$. Callose deposition was visualized with aniline blue using an Olympus IX-71 inverted fluorescence microscope (Tokyo). Scale bars $=500 \mu \mathrm{m}$. B, Levels of hydrogen peroxide $\left(\mathrm{H}_{2} \mathrm{O}_{2}\right)$. C, Relative amount of callose deposition. The relative amount of callose deposition was calculated, using ImageJ software, from microscopy photographs. These experiments were repeated three times with similar results. Statistical analysis was performed using one-way analysis of variance, followed by the Tukey multiple comparison test. The level of significance was set at $P<$ 0.05. The statistics and bar graphs were performed using a GraphPad Prism 8.2 (Graph Pad Software, La Jolla, CA, U.S.A.). 
ROS bursts and callose deposition were also detected in the $N a h G$ transgenic plants, jarl and nprl mutants, and the wildtype Col-0 plants after pretreatment with VMA at $10 \mu \mathrm{g} \mathrm{ml}^{-1}$ at $24 \mathrm{~h}$ and then inoculated with DC3000. After 12 or $24 \mathrm{~h}$, ROS bursts and callose deposition exhibited in these plants are consistent with the disease symptoms (Fig. 8). The results further demonstrated that VMA induces plant defense response via the SA signaling pathway and is partly dependent on NPR1 in Arabidopsis.

\section{VMA triggers defense response to $B$. cinerea through the JA/ET signaling pathway and is dependent on NPR1 in Arabidopsis.}

It is well-known that SA triggering plant immunity is effective for the biotrophic pathogen $P$. syringae, but it is not effective for necrotrophic fungi $F$. graminearum and $B$. cinerea (Shoresh et al. 2005; Vidhyasekaran 2015). In this study, we found that VMA could also induce resistance to necrotrophic pathogen B. cinerea and $F$. graminearum in Arabidopsis. To explain this result, the $N a h G$ transgenic plants, jar1, ein2, and nprl mutants, and the wild-type Col-0 plants were used to determine the resistance induced by VMA to necrotrophic
B. cinerea. The resistance mediated by VMA to $B$. cinerea were not induced in Arabidopsis npr1, jarl, and ein2 mutant plants, but no difference was observed between $N a h G$ transgenic plants and the wild-type Col-0 plants (Fig. 9). This result indicated that VMA triggers plant defense responses to necrotrophic pathogens via JA/ET signaling pathway and is dependent on NPR1.

\section{Transcriptome analysis of Arabidopsis treated by VMA.}

A. thaliana Col-0 plants treated with VMA at $10 \mu \mathrm{g} \mathrm{ml}^{-1}$ for 24 and $48 \mathrm{~h}$ (V24h, V48h) or sterile double distilled (dd) $\mathrm{H}_{2} \mathrm{O}$ (CK24h, CK48 h) were cultured for $24 \mathrm{~h}$ with DC3000 (V24h_P) after treatment with VMA at $10 \mu \mathrm{g} \mathrm{ml} \mathrm{m}^{-1}$ for $24 \mathrm{~h}$ or after treatment with sterile double-distilled $(\mathrm{dd}) \mathrm{H}_{2} \mathrm{O}$ (CK24h_P) for $24 \mathrm{~h}$, and samples were collected for RNA-Seq.

A total of $903,581,638$ raw reads were generated from 18 cDNA libraries (V24h, V48h, CK24h, CK48h, V24h_P, CK24h_P, three biological replicates per treatment), ranging from 41.8 to 70.7 million reads per sample. After quality filtering, 874,364,470 clean reads remained, ranging between 40.6 and 69.0 million per sample. Based on the quality test of the clean reads, the Q20 from all reads was between 96.40 and
A

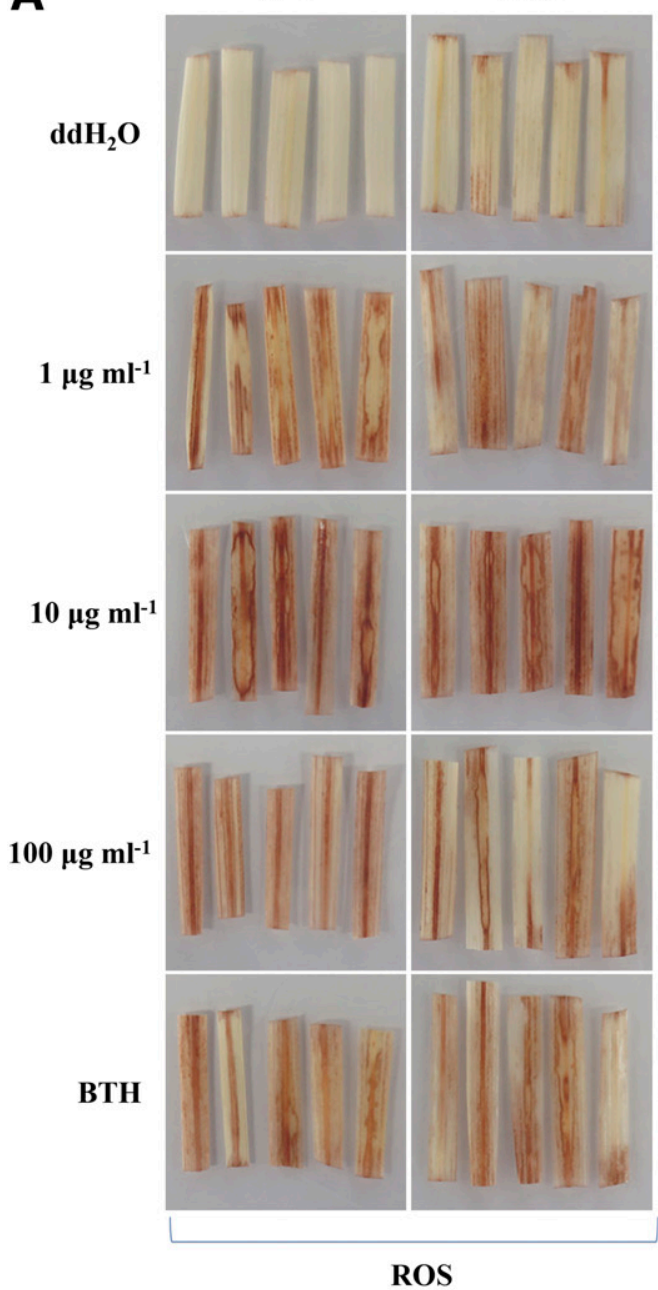

$12 \mathrm{~h}$

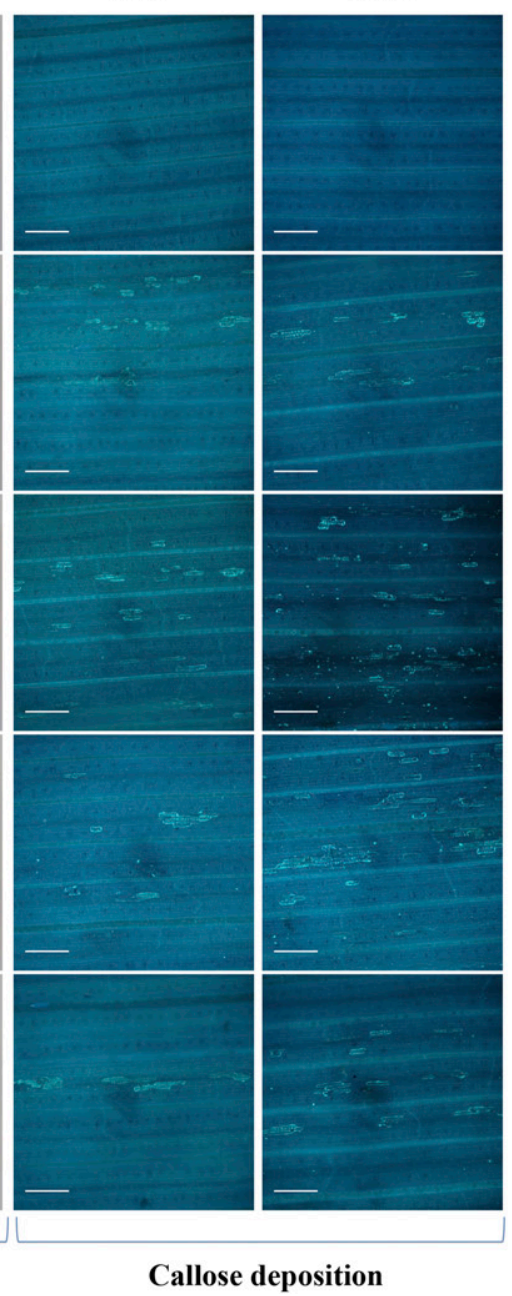

B
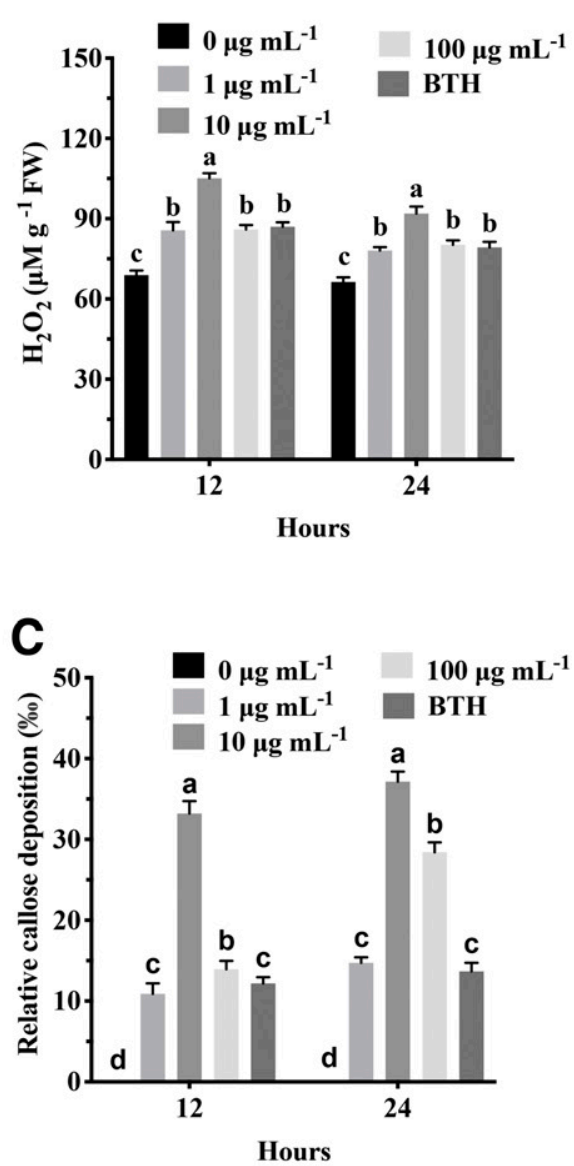

Fig. 5. The defense response was induced by validamycin A (VMA) in leaves of rice. A, Reactive oxygen species (ROS) and callose deposition. B, Levels of $\mathrm{H}_{2} \mathrm{O}_{2}$. C, Relative amount of callose deposition. ROS and callose deposition were detected at 12 and $24 \mathrm{~h}$ after VMA (1, 10 , and $100 \mu \mathrm{g}$ ml $\mathrm{V}^{-1}$ ) or sterile doubledistilled $\mathrm{H}_{2} \mathrm{O}$ and benzo $(1,2,3)$ thiadiazole-7-carbothioic acid (BTH) $\left(100 \mu \mathrm{g} \mathrm{m} \mathrm{m}^{-1}\right)$ had been applied. ROS bursts were detected by diaminobenzidine tetrachloride staining, and photos were then taken with a Canon camera G16 (Tokyo). Callose deposition was visualized with aniline blue using an Olympus IX-71 inverted fluorescence microscope (Tokyo). Scale bars $=200 \mu \mathrm{m}$. These experiments were repeated three times with similar results. Statistical analysis was performed using one-way analysis of variance, followed by the Tukey multiple comparison test. The level of significance was set at $P<0.05$. The statistics and bar graphs were performed using a GraphPad Prism 8.2 (Graph Pad Software, La Jolla, CA, U.S.A.). 
$98.23 \%$, while the Q30 was between 90.68 and $94.65 \%$. About $97.6 \%$ of the clean reads was successfully aligned to the A. thaliana Col-0 reference genome. These results indicated that the gene transcript data were reliable and suitable for further transcriptome analysis (Supplementary Table S1).

A total of 7,646 differentially expressed genes (DEGs) were obtained, and the heat map generated by cluster analysis showed that the expression patterns of most DEGs in the treatment group were different from that in the control group (Supplementary Fig. S7A). Venn diagrams were drawn to show DEGs that are common to both 24- and 48-h treatments and are specific to A. thaliana in response to VMA (Supplementary Fig. S7B). Compared with CK24h (V24h/CK24h), the number of V24h DEGs was 667 in A. thaliana Col-0; 401 genes were upregulated, and 266 genes were downregulated. Compared with CK48h (V48h/CK48h), there were 1,194 DEGs in V48h, 788 upregulated genes and 406 downregulated genes. Compared with CK24h_P (V24h_P/CK24h_P), 1,815 DEGs were found in V24h_P, including 1,004 upregulated genes and 811 downregulated genes. Compared with CK48h (CK24h_P/CK48h), A. thaliana Col-0 inoculated with DC3000 (CK24h_P) attained 6,124 DEGs, including 3,184 upregulated genes and 2,940 downregulated genes (Supplementary Fig. S7C).
To identify the pathways in which DEGs participate, the Kyoto Encyclopedia of Genes and Genomes (KEGG) pathway enrichment analysis was performed. The top 10 enriched pathways in V24h/CK24h, V48h/CK48h, V24h_P/CK24h_P, and CK24h_P/CK48h are shown in Supplementary Tables S2, S3, S4, and S5. There are four common pathways involved in plant hormone signal transduction, plant-pathogen interaction, mitogen-activated protein kinase (MAPK) signaling pathways, and starch and sucrose metabolism (Supplementary Fig. S8A, B, C, and D, respectively).

Both in V24h/CK24h and V48h/CK48h, cyclic nucleotide gated channel (CNGC10), NADPH/respiratory burst oxidase protein (RbohD), calcium-dependent protein kinase (CPK28), and calcium-binding EF-hand family protein and calmodulin (CAM3, CML42) genes were significantly upregulated, but the 'defense, no death' gene (DNDI) encoded a mutated cyclic nucleotide-gated cation channel that was significantly downregulated. In $\mathrm{CK} 24 \mathrm{~h} \_\mathrm{P} / \mathrm{CK} 48 \mathrm{~h}$, the expression of gene $C N G C 10$ was also notably upregulated, but genes, CPK28, RbohD, CAM3, and CAM42 were not effective. However, in V24h_P/CK24h_P, genes CNGC15, CNGC10,CPK28, CPK32, $C A M 3, C M L 38, C M L 42$, and RbohD were significantly upregulated, and gene $D N D 1$ was significantly downregulated. This result indicated that VMA might activate a calcium signature
A

VMA

Pst DC3000

\section{$0 \mathrm{~h}$
$\mathrm{6h}$}

$12 \mathrm{~h}$

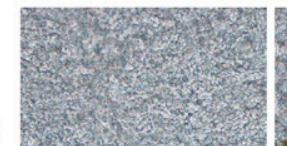

$24 \mathrm{~h}$
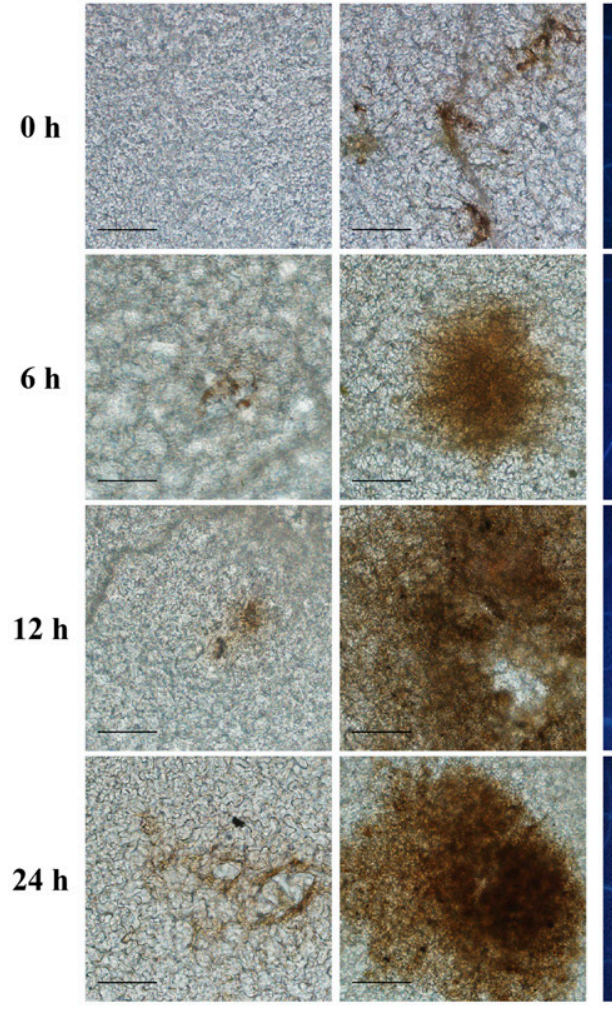

ROS

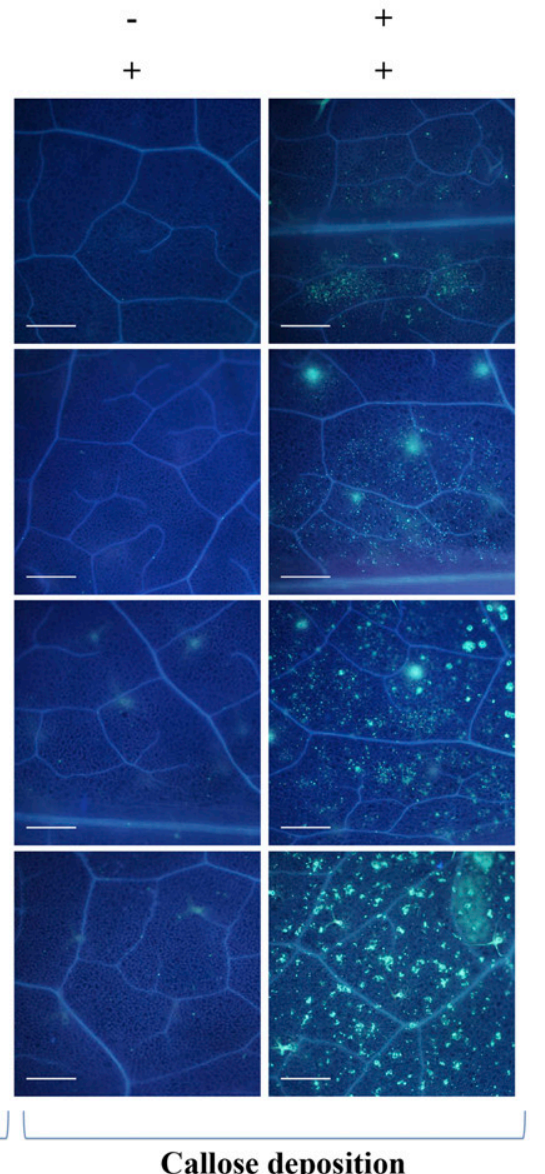

Callose deposition
B
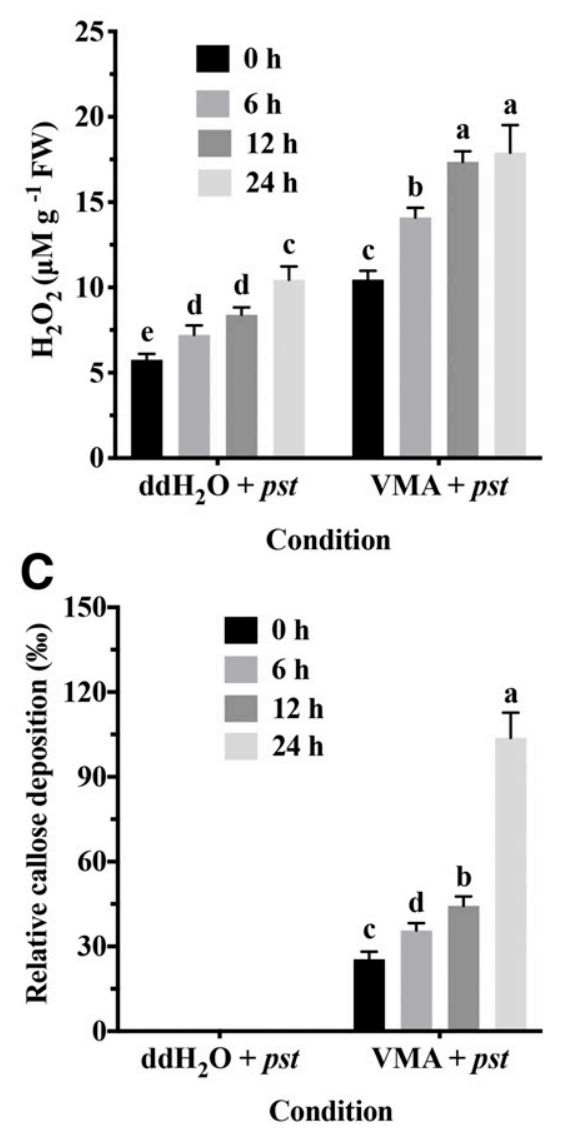

Fig. 6. Combinative effects of validamycin A (VMA) and Pseudomonas syringae pv. tomato DC 3000 on defense responses in Arabidopsis. A, Reactive oxygen species (ROS) and callose deposition. B, Levels of $\mathrm{H}_{2} \mathrm{O}_{2}$. C, Relative amount of callose deposition. The defense responses were tested in accordance with treatments noted in the upper caption panels. Arabidopsis plants were treated with $10 \mu \mathrm{g}$ of VMA per milliliter (VMA+) or double-distilled $\mathrm{H}_{2} \mathrm{O}$ (VMA-) for 24 $\mathrm{h}$ and were observed at $0,6,12$, and $24 \mathrm{~h}$ after pressure-infiltrated inoculation with $P$. syringae pv. tomato DC3000 (Pst DC3000+) suspensions $\left(1 \times 10^{8} \mathrm{CFU}\right.$ $\left.\mathrm{ml}^{-1}\right)$. ROS was detected as described above. Scale bars $=100 \mu \mathrm{m}$. Callose deposition was detected as described above, Scale bars $=500 \mu \mathrm{m}$. The relative amount of callose deposition was calculated, using ImageJ software, from microscopy photographs. These experiments were repeated three times with similar results. Statistical analysis was performed using one-way analysis of variance, followed by the Tukey multiple comparison test. The level of significance was set at $P<0.05$. The statistics and bar graphs were performed using a GraphPad Prism 8.2 (Graph Pad Software, La Jolla, CA, U.S.A.). 
$\left(\mathrm{Ca}^{2+}\right)$ and ROS transduction, and this function was further strengthened when plants interact with pathogens.

In V24h/CK24, V48h/CK48h, and V24h_P/CK24h_P, a MAPK (MPK3) was significantly upregulated. Moreover, in V48h/CK48h and V24h_P/CK24h_P, MPK6, MAP/extracellular signal-regulated kinase (ERK) kinase kinase 1(MEKK1), EF-TU receptor (EFR), and Leu-rich receptor serine/threonine protein kinase (SERK4, BAK1) were also significantly upregulated. This result showed that VMA triggered plant immune response involving in the MAPK signaling pathway.

In V24h/CK24h, the regulatory protein EDS1 involved in upstream SA signaling, acyl-adenylate/thioester forming enzyme (PBS3) related to the biosynthesis of SA, transcriptional factor WRKY41, defense related PR1, ABA receptor (PYL6), auxin/ indole 3-acetic acid (Aux/IAA) inducible genes, Gretchen Hagen3 (GH3s), small auxin upregulated RNAs (SAUR20, SAUR28) genes were significantly upregulated, but in $\mathrm{V} 48 \mathrm{~h} / \mathrm{CK} 48 \mathrm{~h}$, only $P B S 3$ and $G H 3$ were still slightly upregulated, and $A U X / I A A, P Y R / P Y L$, and SAURs genes were downregulated. The genes mentioned above were inhibited or unchanged in CK24h_P/CK48h. The expression of JA receptors (JAZs) was inhibited in V24h/CK24h and V48h/CK48h, and the other genes associated with the JA/ET signal pathway, such as $J A R$ and $E R F 1 / 2$, were unchanged in both V24h/CK24h and $\mathrm{V} 48 \mathrm{~h} / \mathrm{CK} 48 \mathrm{~h}$. In CK24h_P/CK48h, the expression of JAZ, $J A R, E T R$, plant defensin 1.2 (PDF 1.2), and ERF1/2 was significantly upregulated in Arabidopsis infected by DC3000. The expressions of genes NPR1, EDS1, PBS3, PR1, PYL7, and SNF1-related protein kinase involved in the downstream expression of ABA (sucrose nonfermenting 1-related protein kinase 2 [SnRK2]), ABA response element-binding factor (ABF3), AUX/IAA, GH3, SAURs, and PDF1.2 were significantly upregulated in V24h_P/CK24h_P, and the genes JAZ, $J A R 1$, and $E R F 1 / 2$ were still inhibited. PDF1.2 is the maker gene of the JA/ET signal pathway (Pieterse et al. 2006; Vidhyasekaran 2015). The expression of gene PDF1.2 was not changed in V24h/CK24h, but was significantly upregulated in $\mathrm{V} 48 \mathrm{~h} / \mathrm{CK} 48 \mathrm{~h}$. Therefore, this result indicated that VMA can activate the SA and JA/ET signal pathways, the ABA signaling pathway, and the auxin signaling pathway in Arabidopsis.

In addition, the expression level of genes involved in trehalose metabolism was analyzed in Arabidopsis plants pretreated with VMA. In V24h/CK24h, the expression of trehalose-6phosphate synthase TPS 8 was significantly upregulated, on the contrary, the expression of TPS5 and beta-glucosidase genes (BGUL5, BGUL46, BGUL11, and BGUL10) were significantly downregulated. In $\mathrm{V} 48 \mathrm{~h} / \mathrm{CK} 48 \mathrm{~h}$, the expression of TPS5, BGUL5, BGUL46, BGUL11, and BGUL10 genes were still downregulated, but TPS8, TPS1, BGUL42, and BGUL17 were upregulated. This result indicated that VMA upregulated expression of the TPS 8 gene in the early stage of treatment and it was then downregulated, and the expression of betaglucosidase genes were significantly inhibited by VMA.

\section{Verification of DEGs by quantitative real-time reverse transcription PCR (qRT-PCR).}

To validate the DEGs identified by RNA-Seq, 28 DEGs were investigated by qRT-PCR, including EDS1, PBS3, NPR1, and $P R 1$ genes involved in the SA signaling pathway; $P Y L 6, S n R K 2$, and $A B F 3$ involved in the ABA signaling pathway; $G H 3$ and

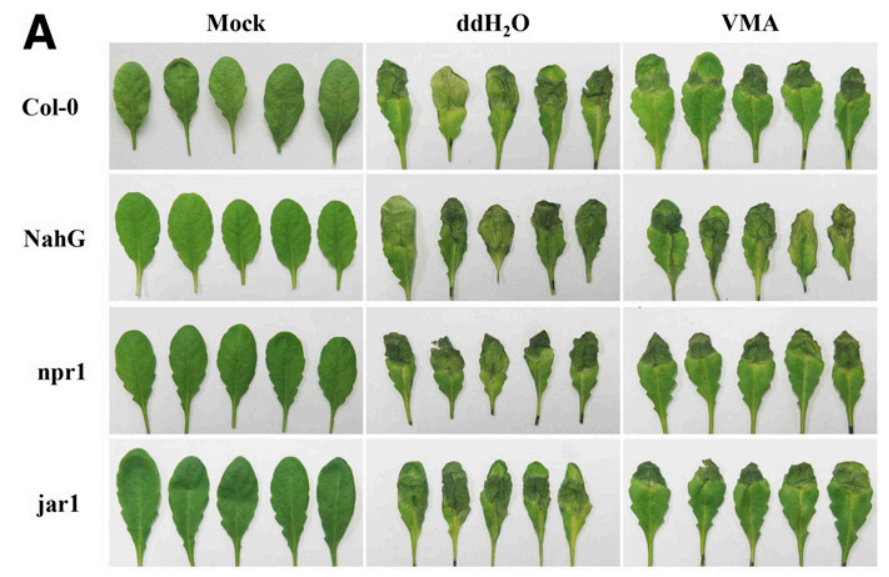

B
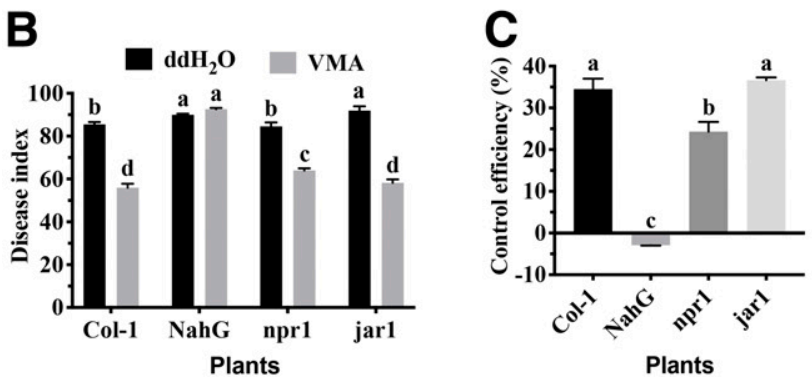

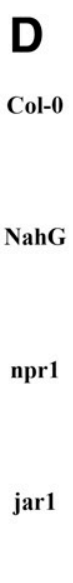

E

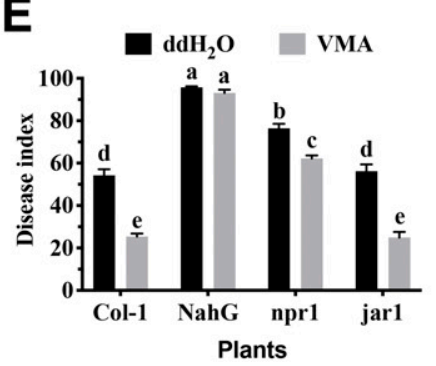

.

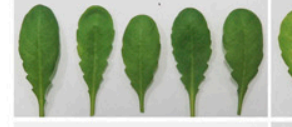

$\mathrm{ddH}_{2} \mathrm{O}$
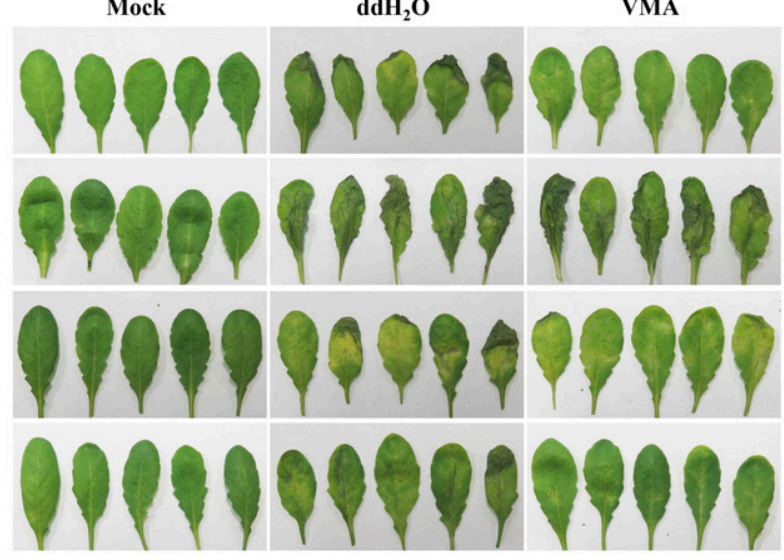

$\mathbf{F}$

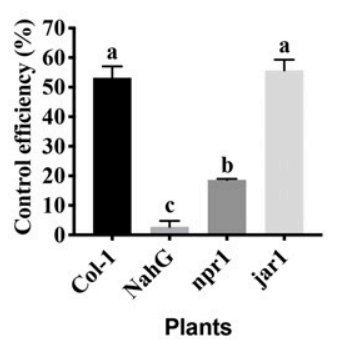

Fig. 7. Validamycin A (VMA)-induced defense response against Pseudomonas syringae pv. tomato DC3000 (DC3000) in the specific genotypes of Arabidopsis plants. A, B, and C, Disease symptoms, disease index, and control efficiency of the plants with infiltrated inoculation with DC3000. The plants were pretreated with $10 \mu \mathrm{g}$ of VMA per milliliter for $24 \mathrm{~h}$ and were then inoculated by infiltrating DC3000 suspension $\left(1 \times 10^{8} \mathrm{CFU} \mathrm{ml}^{-1}\right)$ or sterile double-distilled $(\mathrm{dd}) \mathrm{H}_{2} \mathrm{O}$ into the abaxial side (underside) of the Arabidopsis leaves. D, E, and F, Disease symptoms, disease index, and control efficiency of the plants with sprayed inoculation with DC3000. The plants were pretreated with $10 \mu \mathrm{g}$ of VMA per milliliter for $24 \mathrm{~h}$ and were then inoculated by spraying with DC3000 suspension $\left(1 \times 10^{8} \mathrm{CFU} \mathrm{ml}^{-1}\right)$ or sterile $\mathrm{ddH}_{2} \mathrm{O}$ in the presence of Silwet L-77 $(0.03 \%)$ on the surface of Arabidopsis leaves. The photos were taken and the disease index and control efficiency were measured 3 days after inoculation. Col- $0=$ the wild type Col- 0 plants, NahG $=$ NahG transgenic plants, npr $1=n p r 1$ mutants, jar $1=$ jarl mutants. These experiments were repeated three times with similar results. Statistical analysis was performed using one-way analysis of variance, followed by the Tukey multiple comparison test. The level of significance was set at $P<0.05$. The statistics and bar graphs were performed using a GraphPad Prism 8.2 (Graph Pad Software, La Jolla, CA, U.S.A.). 
SAUR38 involved in the auxin signaling pathway; JARl, JAZ, $E R F 1$, and $P D F 1.2$ involved in the JA/ET signaling pathway; WRKY41, WRKY33, and WRKY25 transcriptional factors involved in the plant hormone signaling pathway; $M A K K 1$, $M A P K 3$, and MAPK6 involved in the MAPK signaling pathway; DND1, CNGC10, CPK28, RbohD, CAM3, and CMLA2 involved in $\mathrm{Ca}^{2+}$ and ROS signals; TPS 8 gene involved in trehalose metabolism; as well as Bglu10 and Bglu5 involved in starch and sucrose metabolism (Supplementary Fig. S9). The AtActin2 gene was used as internal control. All DEGs exhibited the same tendency between RNA-Seq analysis and qRT-PCR results. A high degree of correlation was found between the qRT-PCR results and the RNA-Seq results by comparing the corresponding expression data. These results further confirmed that the transcriptomic profiling data were accurate and reliable.

\section{DISCUSSION}

The attack of plants by various pathogens is the major cause of crop losses. Beyond the immune responses against an intermediate infection, plant resistance can be temporarily induced before pathogen infection and is effective for a certain period to a broad spectrum of pathogens (Nie et al. 2017). Endogenous signaling molecules, such as SA, JA, and ET, activate immune responses and are involved in the regulation of these induced defense responses (Pieterse et al. 2006). Disease resistance of plants can also be induced by some chemical agents, such as 2,6-dichloroisonicotinic acid, $\beta$-aminobutyric acid, benzo $(1,2,3)$ thiadiazole-7-carbothioic acid, probenazole, pyraclostrobin, tricarboxylic acids, riboflavin, and trehalose, and these chemical agents mimic or ingeniously make use of the same pathways that are activated by the endogenous defense signals (Balmer et al. 2018; Conrath et al. 2002; Ma et al. 2013; Pieterse et al. 2006; Zhang et al. 2009). In this study, we proved that VMA, indeed, induces plant defense responses via SA and ET/JA signaling pathway and also exerts a positive influence on ABA and auxin signaling pathways, and this effect has potential for defense against plant pathogens in the field.

The chemical control of plant diseases results in a significant impact on the environment; it is preferable to induce plant
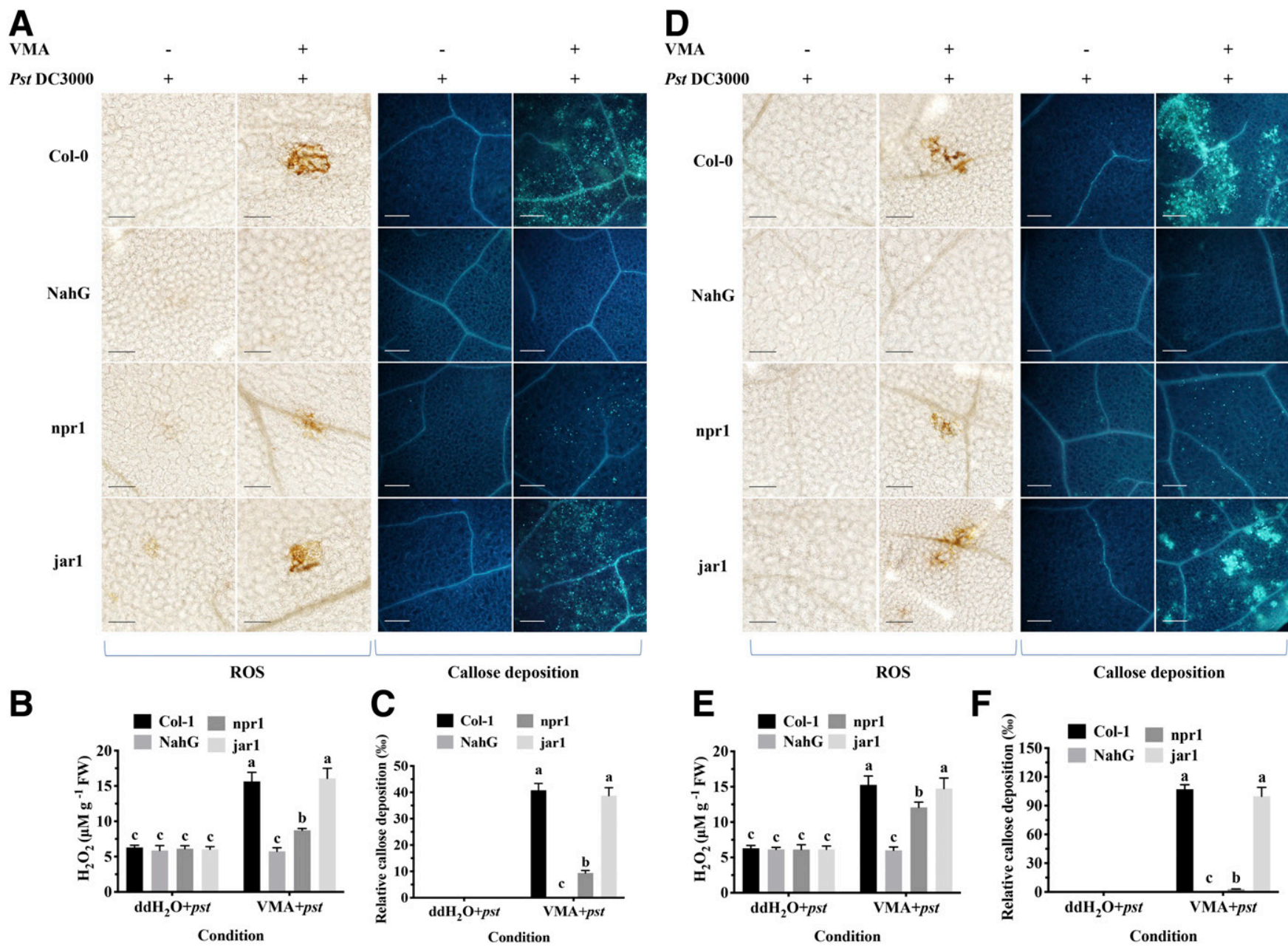

Fig. 8. Combinative effects of validamycin A (VMA) and Pseudomonas syringae pv. tomato DC3000 on defense response in specific genotypes of Arabidopsis. $\mathbf{A}, \mathbf{B}$, and $\mathbf{C}$, Reactive oxygen species (ROS) and callose deposition, levels of $\mathrm{H}_{2} \mathrm{O}_{2}$, and relative amount of callose deposition of the plants after sprayinoculation with DC3000 for $12 \mathrm{~h}$. Arabidopsis plants were treated with $10 \mu \mathrm{g}$ of VMA per milliliter (VMA+) or double-distilled $\mathrm{H}_{2} \mathrm{O}$ (VMA-) for $24 \mathrm{~h}$ and were then inoculated by spraying with $P$. syringae pv. tomato DC3000 suspension $\left(1 \times 10^{8} \mathrm{CFU} \mathrm{ml}^{-1}\right)($ Pst DC3000+) on the surface of Arabidopsis leaves. ROS bursts and callose deposition were detected $12 \mathrm{~h}$ after inoculation, as described above. In photos of ROS bursts, scale bars $=100 \mu \mathrm{m}$. In photos of callose deposition, scale bars $=200 \mu \mathrm{m}$. D, E, and $\mathbf{F}$, ROS and callose deposition, levels of $\mathrm{H}_{2} \mathrm{O}_{2}$, and relative amount of callose deposition of the plants after sprayinoculation with $P$. syringae pv. tomato DC3000 for $24 \mathrm{~h}$. Arabidopsis plants were treated with $10 \mu \mathrm{g}$ of VMA per milliliter (VMA+) or double-distilled $\mathrm{H}_{2} \mathrm{O}$ (VMA-) for $24 \mathrm{~h}$ and were then inoculated by spraying with Pst DC3000+ on the surface of Arabidopsis leaves. After inoculation for 24 h, ROS bursts and callose deposition were detected as described above. In photos of ROS bursts, scale bars $=100 \mu \mathrm{m}$. In photos of callose deposition, scale bars $=200 \mu \mathrm{m}$. Col- $0=$ the wild type Col-0 plants, $\mathrm{NahG}=N a h G$ transgenic plants, npr1 = nprl mutants, jar1 = jarl mutants. These experiments were repeated three times with similar results. Statistical analysis was performed using one-way analysis of variance, followed by the Tukey multiple comparison test. The level of significance was set at $P<0.05$. The statistics and bar graphs were performed using a GraphPad Prism 8.2 (Graph Pad Software, La Jolla, CA, U.S.A.). 
immunity with some environmentally friendly agents to improve plant resistance (Nie et al. 2017; Saijo and Loo 2020; Zhang et al. 2009). Exogenous trehalose treatment triggered reactive oxygen burst, enhanced the activities of defenserelated enzymes, and induced resistance against downy mildew disease of pearl millet and wheat powdery mildew (Govind et al. 2016; Tayeh et al. 2014). In addition, trehalose plays a significant role in various biological processes and cell metabolisms in plants, including growth, development, and responses to abiotic and biotic stresses (John et al. 2017; Tayeh et al. 2014). Plants accumulate trehalose when the potent trehalase inhibitor VMA is supplied to them, which is effective in whole plants (Müller et al. 1995). Moreover, VMA is more economical than trehalose in terms of production and application. Only a few studies have shown that VMA induced plant defense response (Ishikawa et al. 2005; Li et al. 2019; Zhang et al. 2001), and no information about the optimum conditions for inducing the defense response is available. In this study, we verified that VMA is more effective against $P$. syringae, $F$. graminearum, and $B$. cinerea in vivo than in vitro (Figs. 1, 2 and 3; Supplementary Fig. S1). This result is in accordance with the Ishikawa et al. (2005) study finding that VMA is not antifungal in vitro but effectively controls tomato wilt when applied by foliar spray. The key characteristics of effective defense

A

A

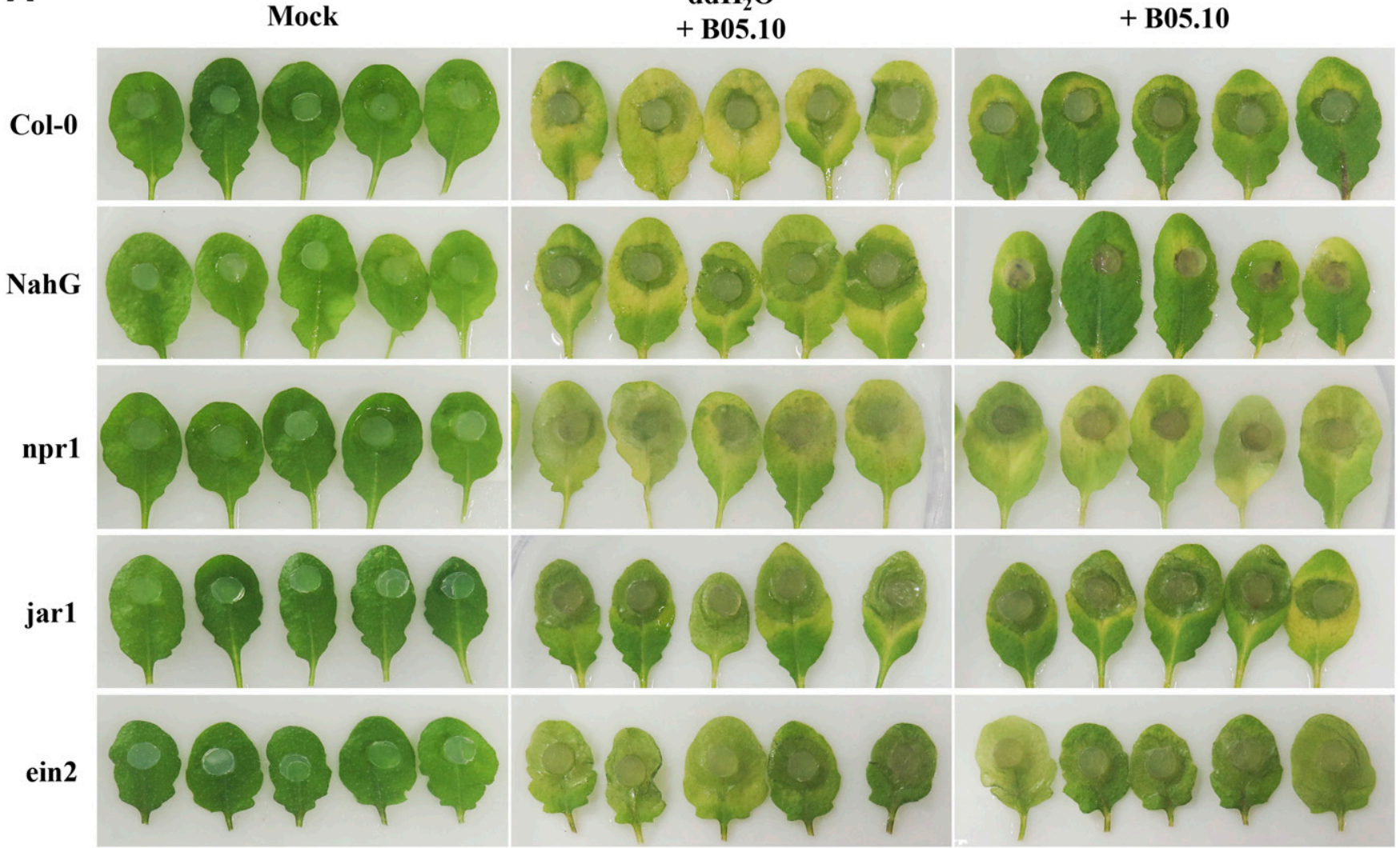

B

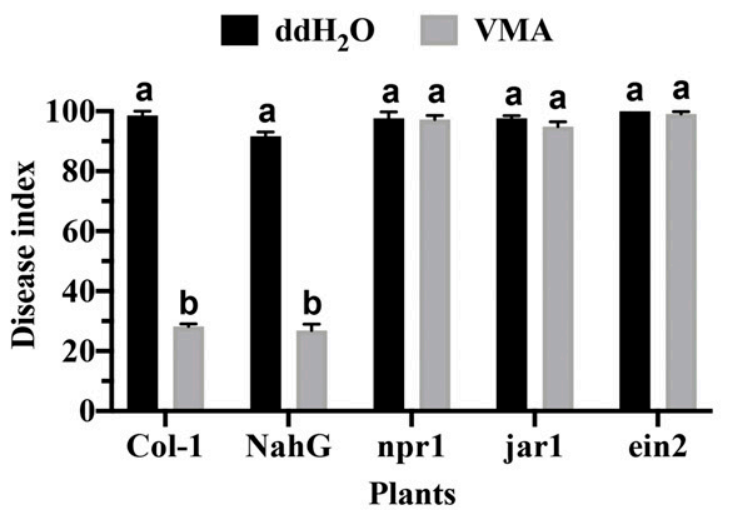

C

Fig. 9. Validamycin A (VMA)-induced defense response against Botrytis cinerea in the specific genotypes of Arabidopsis plants. A, Disease symptoms of plants inoculated with B. cinerea. B and C, Disease index and control efficiency. The plants were pretreated with $10 \mu \mathrm{g}$ of VMA per milliliter (VMA + B05.10) or sterile double-distilled $\mathrm{H}_{2} \mathrm{O}\left(\mathrm{ddH}_{2} \mathrm{O}+\mathrm{B} 05.10\right)$ for $24 \mathrm{~h}$ prior to inoculation with agar plugs (diameter in $\left.5 \mathrm{~mm}\right)$ containing or not containing the mycelium of $B$. cinerea $\mathrm{B} 05.10$. The plants inoculated by agar plugs without the mycelium were regarded as control (Mock). The photos were taken, the disease index and control efficiency were measured 3 days after inoculation. Col- $0=$ the wild type Col- 0 plants, NahG $=N a h G$ transgenic plants, npr $1=n p r 1$ mutants, jar $1=j a r 1$ mutants, ein $2=$ ein 2 mutants. These experiments were repeated three times with similar results. Statistical analysis was performed using one-way analysis of variance, followed by the Tukey multiple comparison test. The level of significance was set at $P<0.05$. The statistics and bar graphs were performed using a GraphPad Prism 8.2 (Graph Pad Software, La Jolla, CA, U.S.A.). 
response are memory, low fitness costs, more robust defense response and better performance, and the further characteristics are broad-spectrum activity and low ecological costs (MartinezMedina et al. 2016). In A. thaliana, we showed that VMAinduced defense response at $10 \mu \mathrm{g} \mathrm{ml}^{-1}$ is stronger than at 1 and $100 \mu \mathrm{g} \mathrm{ml}^{-1}$ (Fig. 4). Plants produced ROS bursts and callose deposition after treatment with $10 \mu \mathrm{g} \mathrm{ml}^{-1}$ VMA from 6 to $48 \mathrm{~h}$, which reached maximum at $24 \mathrm{~h}$ and became stronger when infected by DC3000 (Fig. 6; Supplementary Fig. S2). Moreover, we found that $10 \mu \mathrm{g}$ of VMA per milliliter is also the optimum treatment to induce defense responses in rice and wheat, although the leaves, leaf sheath, and coleoptiles of rice and wheat developed a defense response at different levels (Fig. 5; Supplementary Figs. S3, S4, S5, and S6). These results suggested that using VMA as a plant immune activator to control broad-spectrum plant diseases will be effective and economical.

SA and JA/ET signaling pathways play an important role in systemic resistance of plants (Achuo et al. 2004; Shoresh et al.

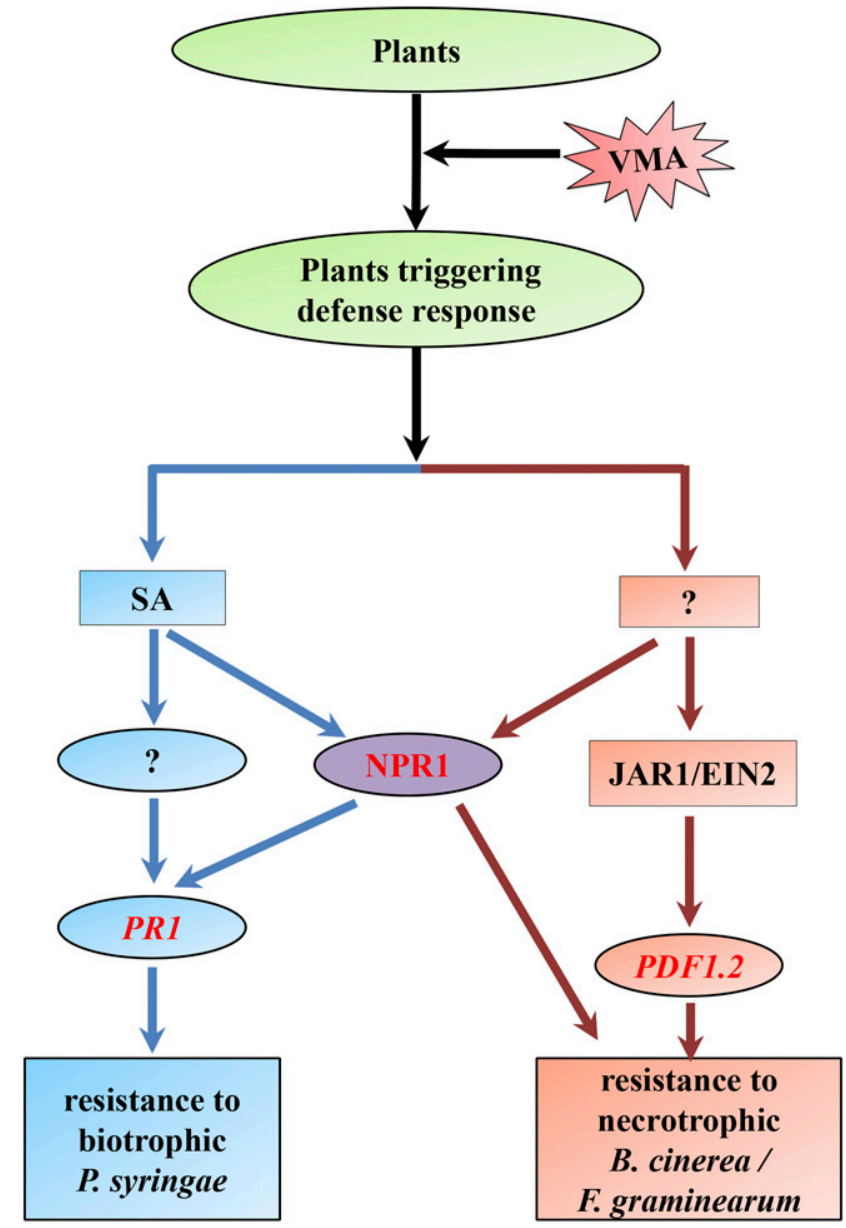

Fig. 10. A proposed model of plant defense response triggered by validamycin A (VMA). When Arabidopsis plants were pretreated with VMA, the systemic resistance to both biotrophic (Pseudomonas syringae) and necrotrophic (Botrytis cinerea and Fusarium graminearum) pathogens is induced. VMA-induced resistance to $P$. syringae was not induced in NahG plants and was partially decreased in $n p r l$ mutants, but no difference was observed between jarl mutants and the wild-type Col-0, indicating that VMA triggers systemic resistance to biotrophic pathogens via the salicylic acid (SA) signaling pathway and is partly dependent on NPR1. VMAinduced resistance to $B$. cinerea was not induced in $n p r 1$, jarl, and ein2 mutants, but no difference was observed between $N a h G$ plants and the wildtype Col-0, indicating that VMA activates resistance to necrotrophic pathogens through the jasmonic acid/ethylene (JA/ET) signaling pathway and is fully dependent on NPR1.
2005; Vidhyasekaran 2015). Riboflavin induced $\mathrm{H}_{2} \mathrm{O}_{2}$ burst, hypersensitive cell death, and callose deposition in A. thaliana, and the defense process is independent of SA and JA/ET but needed NPR1 (Zhang et al. 2009). Bacillus cereus AR156 induced systemic resistance against $B$. cinerea in Arabidopsis depending on the JA/ET-signaling pathway and NPR1 but not on SA (Nie et al. 2017). Citrate and fumarate showed no direct antimicrobial effect but induced a response involving SA and phytoalexin camalexin against DC3000 in Arabidopsis (Balmer et al. 2018). In this study, we found that the system resistance to both biotrophic ( $P$. syringae) and necrotrophic (B. cinerea and $F$. graminearum) pathogens is induced when plants were pretreated with VMA. We compared the potential of VMAinduced resistance to $P$. syringae in NahG plants, nprl and jarl mutants, and the wild-type Col-0 (Figs. 7 and8) and found that VMA-induced resistance to biotrophic pathogens is via the SA signaling pathway and partly dependent on NPR1. NPR1, an important regulator downstream of SA, positively regulated the expression of the defense genes (Mou et al. 2003). Interestingly, the defense response mediated by VMA was significantly weaker in nprl mutants than in wild-type Col-0, suggesting the existence of factors other than NPR1. We also compared the potential of VMA-induced resistance to B. cinerea in $N a h G$ plants, nprl, jarl, and ein2 mutants, and wild-type Col-0 (Fig. 9) and found that VMA-induced resistance to necrotrophic pathogens involves the JA/ET signaling pathway and is fully dependent on NPR1. The plant immune elicitor properties of VMA will provide a valuable tool for controlling a broad spectrum of crop diseases and reducing the use of chemical pesticides.

In plant defense responses, SA, JA/ET, ABA, and auxin signaling pathways are interconnected, resulting in overlap, synergism, and antagonism, and the crosstalk between defense signaling pathways may provide the plant with a powerful regulatory network (Pieterse et al. 2006; Vidhyasekaran 2015). High-throughput RNA sequencing has been widely used to identify some regulatory networks and quantify the transcription levels of genes (Maleck et al. 2000; Xu et al. 2019). Exogenous trehalose triggered a signal transduction pathway in tobacco which involves calcium and ROS-mediated signaling (Shi et al. 2019). In this study, transcriptomic analysis revealed that VMA upregulated the expression of DND1, CNGC, $C a M / C M L$, and $C P K$ genes, involving $\mathrm{Ca}^{2+}$, ROS, and nitric oxide (NO) signals (Supplementary Figs. S8 and S9). This result is consistent with the report by Shi et al. (2019), implying VMA may affect the production of trehalose in plant cells which further affected $\mathrm{Ca}^{2+}$ and ROS or NO signals. In addition, we found that the expression of $M A K K 1$ and $M A P K 3$ genes was also significantly upregulated by VMA, but Shi et al. (2019) reported that no $M P K 3, M P K 4$, and MPK6-like genes were observed in the DEGs. Therefore, we presumed that the defense response mediated by VMA is not only due to the accumulation of trehalose but also the characteristics of VMA itself.

The upstream events of the SA signaling pathway are involved in G-proteins, $\mathrm{Ca}^{2+}$, MAPK cascades, and ROS and NO signaling, and the downstream events have been known to generate SA conjugates, ROS, a MAPK signaling cascade, WRKY transcription factors, NPRl, and pathogenesis-related (PR) genes (Liu and Lam 2019; Vidhyasekaran 2015). NPR1 positively regulates the expression of $\mathrm{PR}$ genes via interaction with transcription factors. However, in some cases, the induction of PR genes is regulated by WRKY transcription factors independent of NPR1, such as rice WRKY45 (Shimono et al. 2007). JA/ET signaling pathways play an important role in the induced systemic resistance and are associated with expression of the genes encoding PDF1.2 (Nie et al. 2017). The 
responses of the ABA signaling pathway to various abiotic stresses, especially drought stress, are mediated by the ABA receptor (PYR/PYL), type 2C protein phosphatases, and SnRK2s (Yu et al. 2019). The auxin signaling pathway is involved in a more complex interplay with various defensesignaling systems and is modulated by Aux/IAA repressors and the auxin response factor (Hayashi 2012). In our transcriptomic analysis, VMA increased the expression levels of the genes $E D S 1, P B S 3, N P R 1$, and $P R 1$ in the SA signaling pathway and transcription factors WRKY41, WRKY25, and WRKY33 (Supplementary Figs. S8 and S9), which is consistent with the above-described results indicating that VMA triggers a defense response involving the SA signaling pathway and NPR1. Although there was no up-regulated expression of some genes upstream of JA/ET, the expression level of gene PDF1.2 was upregulated when plants were pretreated with VMA for $48 \mathrm{~h}$, which indicates that VMA-induced resistance is effective against necrotrophic pathogens. Therefore, we proposed a model that VMA-induced resistance to biotrophic and necrotrophic pathogens involved SA, the JA/ET signal pathway, and is dependent on NPR1 (Fig. 10).

In addition, VMA also upregulated the expression of genes $P Y R / P Y L, S n R K 2$, and $A B F 3$ in the ABA signaling pathway and $A U X / I A A, G H 3$, and $S A U R$ genes in the auxin signaling pathway. In recent years, some studies showed that trehalose can improve the tolerance of plants and upregulate the expression of ABA catabolism genes and ABA signaling-related genes (Ali and Ashraf 2011; Lyu et al. 2018; Yu et al. 2019). Therefore, VMA activating the ABA signaling pathway may result from trehalose accumulation. Müller et al. (1995) reported that trehalase activity can be strongly increased by exogenous auxin analogs, indirectly supporting the results that VMA is involved in the auxin signaling pathway in plants. $\mathrm{Ca}^{2+}$ and ROS signatures can modulate plant phytohormone signal transduction, and phytohormone signal pathways also regulate $\mathrm{Ca}^{2+}$ and ROS signatures composing a complex regulation network (Vidhyasekaran 2015). Although some studies showed that trehalose can induce a defense response following ROS, ionic imbalance, and programmed cell death (Bae et al. 2005; Gao et al. 2013; Tayeh et al. 2014; Yang et al. 2014). However, there are no cues associated with the defense response signaling pathway induced by trehalose. Through RNA-Seq analysis in this study, we comprehensively demonstrated a regulation network involving $\mathrm{Ca}^{2+}$, ROS, SA, JA/ET, ABA, and auxin signaling pathways activated by VMA.

In the trehalose metabolism pathway, only the expression of gene TPS 8 upregulated after treatment with VMA for $24 \mathrm{~h}$ and downregulated after $48 \mathrm{~h}$ (Supplementary Figs. S8 and S9). This result indicated that $10 \mu \mathrm{g}$ of VMA per milliliter has just a slight effect on trehalose metabolism. Müller et al. (1995) reported that $30 \mu \mathrm{mol}$ of VMA per liter accumulated trehalose up to $8 \%$ of the dry weight in primary leaves of soybean without any detectable impairment of growth or health. Therefore, $10 \mu \mathrm{g}$ of VMA per milliter is safe and does not impair the health of plants. In addition, in glucose metabolism pathways, only $\beta$-glucosidase (BGLU) genes were significantly inhibited. These BGLU genes were enriched in the pathway of cellulose decomposition, one probable cause is that VMA can be easily hydrolyzed to VAA by glucosidase in plants. VAA can be decomposed into valienamine and validamine, which inhibits the activity of glucosidase, but the mechanism is unclear at present (Ishikawa et al. 2004, 2005). Taken together, our findings confirmed that VMA is an effective, broad-spectrum, safe, economical, and environmentally-friendly plant immune elicitor, induces plant system resistance to both biotrophic and necrotrophic pathogens, and activates a regulation network involving $\mathrm{Ca}^{2+}$, ROS, SA, JA/ET, ABA, and auxin signaling pathways.

\section{MATERIALS AND METHODS}

\section{Plant material.}

A. thaliana ecotype Col-0, the mutant plants nprl (deletion of transcription factor NPR1), jarl (deletion of jasmonate: amino acid synthetase), ein2 (block ethylene stimulation of flavonol synthesis), and transgenic $N a h G$ (salicylate hydroxylase) plants used in this study were provided by $\mathrm{H}$. Dong and D. Niu from Nanjing Agricultural University, Nanjing, China. Seeds were chilled at $4^{\circ} \mathrm{C}$ for 5 days and were sown into $200-\mathrm{ml}$ pots containing a mixture of soil and vermiculite. The plots were maintained at $22^{\circ} \mathrm{C}$ in chambers with a 12 -h photoperiod. All plants were used for the experiments when they were 40 days old (Nie et al. 2017; Zhang et al. 2009).

\section{VMA treatments and pathogens.}

VMA (purity 98.5\%) was purchased from Sangon Biotech Co., Ltd. (Shanghai, China) and was dissolved in sterile distilled $\mathrm{H}_{2} \mathrm{O}$ containing $0.03 \%$ Silwet L-77 (Sangon). Arabidopsis plants were sprayed with VMA $(0.1,1,10$, and $100 \mu \mathrm{g}$ $\mathrm{ml}^{-1}$ ) or sterile distilled $\mathrm{H}_{2} \mathrm{O}$ containing $0.03 \%$ Silwet L-77.

DC3000 was provided by $\mathrm{H}$. Dong from Nanjing Agricultural University, was stored at $-80^{\circ} \mathrm{C}$, and was cultured on Luria Bertani agar medium $(0.5 \%$ yeast extract, $1 \%$ tryptone, $1 \%$ $\mathrm{NaCl}$, and $1.6 \%$ agar power, $\mathrm{pH} 7.0$ ) containing rifampicin and kanamycin $\left(50 \mu \mathrm{g} \mathrm{ml} \mathrm{m}^{-1}\right.$ each). F. graminearum $\mathrm{PH}-1$ and $B$. cinerea $\mathrm{B} 05.10$ were cultured at $25^{\circ} \mathrm{C}$ on potato dextrose agar (PDA) medium (200 $\mathrm{g}$ of potato, $20 \mathrm{~g}$ of dextrose, $16 \mathrm{~g}$ of agar, and 1 liter of water).

\section{Effect of VMA on growth of the pathogens.}

The optical density at $600 \mathrm{~nm}\left(\mathrm{OD}_{600}\right)$ of $\mathrm{DC} 3000$ was detected every $2 \mathrm{~h}$ in King's B liquid medium ( $20 \mathrm{~g}$ of peptone, $1.5 \mathrm{~g}$ of $\mathrm{KH}_{2} \mathrm{PO}_{4}, 1.5 \mathrm{~g}$ of $\mathrm{MgSO}_{4} \cdot 7 \mathrm{H}_{2} \mathrm{O}, 10 \mathrm{ml}$ of glycerol, and 1 liter of water, $\mathrm{pH} 7.2$ ) amended with VMA at $0,0.1,1,10$, and $100 \mu \mathrm{g} \mathrm{ml}^{-1}$. The extracellular polysaccharide production of DC3000 was determined when the bacteria had grown to a specific population density $\left(\mathrm{OD}_{600}=2.0\right)$ and was measured with phenol-sulfuric acid method as previously described (Duan et al. 2013). The growth of $F$. graminearum and B. cinerea were measured on PDA amended with VMA at 0 , $0.1,1,10$, and $100 \mu \mathrm{g} \mathrm{ml}^{-1}$.

\section{Pathogen inoculation and disease assays.}

DC3000 was transferred to King's B liquid medium and the culture was shaken for $12 \mathrm{~h}$ at $28^{\circ} \mathrm{C}$. The bacteria suspension was centrifuged $\left(8,000 \mathrm{rpm}, 4^{\circ} \mathrm{C}\right)$ for $10 \mathrm{~min}$ and was suspended in a sterile $10 \mathrm{mM} \mathrm{MgSO}_{4}$ solution. Arabidopsis leaves were inoculated by spraying with DC3000 suspension $\left(1 \times 10^{8}\right.$ $\mathrm{CFU} \mathrm{ml} \mathrm{m}^{-1}$ ) or sterile $\mathrm{ddH}_{2} \mathrm{O}$ in the presence of Silwet L-77 $(0.03 \%)$ or by infiltrating DC3000 suspension $\left(1 \times 10^{8} \mathrm{CFU}\right.$ $\mathrm{ml}^{-1}$ ) or sterile $\mathrm{ddH}_{2} \mathrm{O}$ into the abaxial side (underside) of the Arabidopsis leaves.

F. graminearum was cultured on PDA for 5 to 7 days at $25^{\circ} \mathrm{C}$. The cultures were washed with sterile $\mathrm{ddH}_{2} \mathrm{O}$, were scraped with a soft hairbrush, and were filtered with Miracloth to remove debris; the larger mycelia and the smaller pieces of mycelia fragments were harvested. A 1-ml needleless syringe was used for infiltrating a suspension of fungal mycelial fragments or sterile $\mathrm{ddH}_{2} \mathrm{O}$ into the abaxial side (underside) of the Arabidopsis leaves.

B. cinerea strain was cultured on PDA for 7 days. According to a previous study, sterilized potato slices were used for conidiation assays (Ren et al. 2018). Spores were collected with sterile $\mathrm{ddH}_{2} \mathrm{O}$ and were adjusted to a final concentration of $1 \times$ $10^{6}$ spores per milliliter. Inoculation was carried out by depositing a $10-\mu \mathrm{l}$ spore suspension or sterile $\mathrm{ddH}_{2} \mathrm{O}$ containing 
$0.03 \%$ Silwet L-77 on one side of the Arabidopsis leaves or by putting an agar plus containing mycelia of $B$. cinerea on Arabidopsis leaves.

After inoculation, plants were covered with a transparent plastic wrap for $24 \mathrm{~h}$ to maintain high humidity and promote infection. There were 12 replicated plants for each treatment, unless otherwise stated, and all the experiments were repeated three times. Symptoms of Arabidopsis leaves were recorded 3 to 7 days postinoculation (dpi) and the pathogen populations in leaves were determined 1 to 3 dpi. Disease symptoms were recorded 7 days after transplantation according to the following keys: 0 for no lesion; 1 for 0 to $25 \%$; 2 for 25 to $50 \%$; 3 for 50 to $75 \%$; 4 for more than $75 \%$ of infected lesion covered with the whole plant. Disease indices (DI) and control efficiency were calculated using the following formulas.

$$
\begin{aligned}
& D I=\sum \text { (key value } \\
& \quad \times \text { the number of plants for the corresponding key value }) \\
& \quad / \text { (the highest key value } \times \text { total number of plants }) \times 100
\end{aligned}
$$

$$
\begin{aligned}
& \text { Control efficiency }(\%)= \\
& {[\text { (control disease index }- \text { treatment disease index })} \\
& \text { / control disease }] \times 100
\end{aligned}
$$

\section{Quantification of the pathogen in Arabidopsis leaves.}

The biomass of bacteria in Arabidopsis leaves were determined at 6, 12, and $24 \mathrm{~h}$ after inoculation with DC3000. The leaves $(1 \mathrm{~g})$ were cleaned with $70 \%$ ethanol for surface sterilization, were washed three times with sterile $\mathrm{ddH}_{2} \mathrm{O}$, and were ground in $9 \mathrm{ml}$ of $0.85 \% \mathrm{NaCl}$ solution. The suspensions were diluted and spread on plates containing King's B solid medium amended with $50 \mu \mathrm{g}$ of rifampicin and $50 \mu \mathrm{g}$ of kanamycin per milliliter.

The quantification of pathogenic fungi in leaves was determined at 1 and 3 days after inoculation, using qRT-PCR. The total DNA of infected leaf tissue was extracted using a plant genomic DNA kit (Tiangen, Beijing). Primers designed to the genes FgActin and BcActin were used, respectively, to monitor the amount of $F$. graminearum and $B$. cinerea relative to Arabidopsis AtActin2.

\section{Plant defense responses assays.}

The levels of $\mathrm{H}_{2} \mathrm{O}_{2}$ were determined with $\mathrm{H}_{2} \mathrm{O}_{2}$ content detection reagent kits (Solarbio, Beijing), according to manufacturer instructions. ROS accumulation was also visualized with a light microscope by staining the Arabidopsis leaves with a $1 \mathrm{mg} \mathrm{ml}^{-1}$ solution of 3,3'-diaminobenzidine tetrachloride, $\mathrm{pH} 3.8$, for $12 \mathrm{~h}$ in the dark at $25^{\circ} \mathrm{C}$, and then being decolored with $96 \%$ (vol/vol) ethanol.

Callose deposition was visualized with aniline blue. Arabidopsis leaves were infiltrated and immersed in $96 \%$ (vol $/ \mathrm{vol})$ ethanol, were incubated in $60^{\circ} \mathrm{C}$ for $30 \mathrm{~min}$ until they were free of chlorophyll, were gently rinsed with $\mathrm{ddH}_{2} \mathrm{O}$, and were then stained with aniline blue solution $(0.01 \%$ aniline blue, 150 $\mathrm{mM} \mathrm{K}_{2} \mathrm{HPO}_{4}, \mathrm{pH} 9.5$ ) in the dark for $4 \mathrm{~h}$ at $25^{\circ} \mathrm{C}$. Leaves were observed with a fluorescence microscope under ultraviolet light.

\section{RNA-Seq and transcriptome analysis.}

A. thaliana Col- 0 plants were collected and stored at $-80^{\circ} \mathrm{C}$ for RNA-Seq after 24 and $48 \mathrm{~h}$, were sprayed with $10 \mu \mathrm{g}$ of VMA per milliliter (V24h, V48h) and sterile $\mathrm{ddH}_{2} \mathrm{O}$ (CK24h, CK48h). Plants pretreated with $10 \mu \mathrm{g}$ of VMA per milliliter for $24 \mathrm{~h}$ were incubated for $24 \mathrm{~h}$ with DC3000 (V24h_P), and plants pretreated with sterile $\mathrm{ddH}_{2} \mathrm{O}$ were incubated for $24 \mathrm{~h}$ with DC3000, (CK24h_P) was also collected and stored at $-80^{\circ} \mathrm{C}$ for RNA-Seq.
Total RNA isolation as well as the construction and sequencing of cDNA libraries of $A$. thaliana were conducted by Novogene Bioinformatics Technology (Beijing, China). Briefly, sequencing libraries were generated, using NEBNext Ultra RNA Library Prep Kit for Illumina (NEB, Ipswich, MA, U.S.A.), following manufacturer recommendations. The clustering of samples was performed on a cBot Cluster Generation System using TruSeq PE Cluster Kit v3-cBot-HS (Illumina) according to the manufacturer's instructions. After cluster generation, library preparations were sequenced on an Illumina Hiseq platform and 125-bp or 150-bp paired-end reads were generated. The index of the reference genome was built using Bowtie v2.2.3 and paired-end clean reads were aligned to the reference genome using TopHat v2.0.12. The differential expression analysis of two conditions was performed using the DESeq R package (1.18.0). The resulting $P$ values were adjusted using the Benjamini and Hochberg approach for controlling false discovery rate. Genes with an adjusted $P$ value $<$ 0.05 , found by DESeq, were assigned as differentially expressed. The sequence reads of RNA-Seq data have been deposited in the National Center for Biotechnology Information Sequence Read Archive database under accession numbers SRR10256658 to SRR10256667 as part of BioProject PRJNA565687.

\section{RNA extraction and qRT-PCR analysis of DEGs.}

Total RNA was extracted from Arabidopsis leaves using Trizol reagent (Invitrogen, Waltham, MA, U.S.A.) following manufacturer protocols. RNA degradation and contamination were monitored on $1 \%$ agarose gels. The NanoPhotometer spectrophotometer (Implen, Westlake Village, CA, U.S.A.) was used to check RNA purity. Total RNA was reverse-transcribed to cDNA using the HiScript II QRT SuperMix for qPCR (+gDNA wiper) (Vazyme, Nanjing, China). PCR primers (Supplementary Table S6) were designed using Primer 5.0. qRT-PCR performed with the CFX Connect real-time PCR detection system (Bio-Rad, Irvine, CA, U.S.A.). Actin was used as the reference gene and reactions were conducted at $95^{\circ} \mathrm{C}$ for $5 \mathrm{~min}, 40$ cycles of $95^{\circ} \mathrm{C}$ for $10 \mathrm{~s}, 60^{\circ} \mathrm{C}$ for $30 \mathrm{~s}$. Three biological replicates for each treatment and three technical replicates for each gene were performed, and the relative expression level was calculated with the $2^{-\Delta \Delta \mathrm{Ct}}$ cycle threshold method as previously described.

\section{Statistical analysis.}

Each treatment was conducted with three replicates. Statistical analysis was performed using one-way analysis of variance, followed by the Tukey multiple comparison test. The level of significance was set at $P<0.05$. The statistics and bar graphs were performed using a GraphPad Prism 8.2 (Graph Pad Software, La Jolla, CA, U.S.A.).

\section{ACKNOWLEDGMENTS}

We thank S. He (Michigan State University) for reviewing the manuscript. We thank H. Dong and D. Niu (Nanjing Agricultural University) for providing Arabidopsis mutants.

\section{LITERATURE CITED}

Achuo, E. A., Audenaert, K., Meziane, H., and Hofte, M. 2004. The salicylic acid-dependent defence pathway is effective against different pathogens in tomato and tobacco. Plant Pathol. 53:65-72.

Ali, Q., and Ashraf, M. 2011. Induction of drought tolerance in maize (Zea mays L.) due to exogenous application of trehalose: Growth, photosynthesis, water relations and oxidative defence mechanism. J. Agron. Crop Sci. 197:258-271.

Bae, H. H., Herman, E., Bailey, B., Bae, H. J., and Sicher, R. 2005. Exogenous trehalose alters Arabidopsis transcripts involved in cell wall 
modification, abiotic stress, nitrogen metabolism, and plant defense. Physiol. Plant. 125:114-126.

Balmer, A., Pastor, V., Glauser, G., and Mauch-Mani, B. 2018. Tricarboxylates induce defense priming against bacteria in Arabidopsis thaliana. Front. Plant Sci. 9:1221.

Conrath, U., Pieterse, C. M. J., and Mauch-Mani, B. 2002. Priming in plantpathogen interactions. Trends Plant Sci. 7:210-216.

Duan, Y., Ge, C., Liu, S., Chen, C., and Zhou, M. 2013. Effect of phenylpyrrole fungicide fludioxonil on morphological and physiological characteristics of Sclerotinia sclerotiorum. Pestic. Biochem. Physiol. 106:61-67.

Gao, J., Wang, N., Xu, S., Li, Y., Wang, Y., and Wang, G. 2013. Exogenous application of trehalose induced $\mathrm{H}_{2} \mathrm{O}_{2}$ production and stomatal closure in Vicia faba. Biol. Plant. 57:380-384.

Govind, S. R., Jogaiah, S., Abdelrahman, M., Shetty, H. S., and Tran, L. S. 2016. Exogenous trehalose treatment enhances the activities of defenserelated enzymes and triggers resistance against downy mildew disease of Pearl Millet. Front. Plant Sci. 7:1593.

Hayashi, K. 2012. The interaction and integration of auxin signaling components. Plant Cell Physiol. 53:965-975.

Ishikawa, R., Shirouzu, K., Nakashita, H., Lee, H. Y., Motoyama, T. Yamaguchi, I., Teraoka, T., and Arie, T. 2005. Foliar spray of validamycin a or validoxylamine a controls tomato fusarium wilt. Phytopathology 95:1209-1216.

Ishikawa, R., Suzuki-Nishimito, M., Fukuchi, A., and Matsuura, K. 2004. Effective control of cabbage black rot by validamycin A and its effect on extracellular polysaccharide production of Xanthomonas campestris pv. campestris. J. Pestic. Sci. 29:209-213.

Iwasa, T., Yamamoto, H., and Shibata, M. 1970. Studies on validamycins, new antibiotics. I. Streptomyces hygroscopicus var. limoneus nov. var. validamycin-producing organism. Jpn. J. Antibiot. 23:595-602.

John, R., Raja, V., Ahmad, M., Jan, N., Majeed, U., Ahmad, S., Yaqoob, U., and Kaul, T. 2017. Trehalose: metabolism and role in stress signaling in plants. Pages 261-275 in: Stress signaling in plants:genomics and proteomics perspective. M. Sarwat, ed. Springer Press, Cham.

Kido, Y., Nagasato, T., Ono, K., Fujimoto, Y., Uyeda, M., and Shibata, M. 1986. Change in a cell wall component of Rhizoctonia solani inhibited by validamycin. Agric. Biol. Chem. 50:1519-1525.

Li, J., Duan, Y., Bian, C., Pan, X., Yao, C., Wang, J., and Zhou, M. 2019. Effects of validamycin in controlling Fusarium head blight caused by Fusarium graminearum: Inhibition of DON biosynthesis and induction of host resistance. Pestic. Biochem. Physiol. 153:152-160.

Liu, J. Z., and Lam, H. M. 2019. Signal transduction pathways in plants for resistance against pathogens. Int. J. Mol. Sci. 20:2335.

Lyu, J. I., Park, J. H., Kim, J. K., Bae, C. H., Jeong, W. J., Min, S. R., and Liu, J. 2018. Enhanced tolerance to heat stress in transgenic tomato seeds and seedlings overexpressing a trehalose-6-phosphate synthase/phosphatase fusion gene. Plant Biotechnol. Rep. 12:399-408.

Ma, C., Wang, Z., Kong, B., and Lin, T. 2013. Exogenous trehalose differentially modulate antioxidant defense system in wheat callus during water deficit and subsequent recovery. Plant Growth Regul. 70: 275-285.

Maleck, K., Levine, A., Eulgem, T., Morgan, A., Schmid, J., Lawton, K. A., Dangl, J. L., and Dietrich, R. A. 2000. The transcriptome of Arabidopsis thaliana during systemic acquired resistance. Nat. Genet. 26:403-410.

Martinez-Medina, A., Flors, V., Heil, M., Mauch-Mani, B., Pieterse, C. M. J., Pozo, M. J., Ton, J., van Dam, N. M., and Conrath, U. 2016 Recognizing plant defense priming. Trends Plant Sci. 21:818-822.

Mou, Z., Fan, W., and Dong, X. 2003. Inducers of plant systemic acquired resistance regulate NPR1 function through redox changes. Cell 113 935-944.

Müller, J., Boller, T., and Wiemken, A. 1995. Effects of validamycin A, a potent trehalase inhibitor, and phytohormones on trehalose metabolism in roots and root nodules of soybean and cowpea. Planta 197:362-368.

Nie, P., Li, X., Wang, S., Guo, J., Zhao, H., and Niu, D. 2017. Induced systemic resistance against Botrytis cinerea by Bacillus cereus AR156 through a JA/ET- and NPR1-dependent signaling pathway and activates PAMP-triggered immunity in Arabidopsis. Front. Plant Sci. 8:238.
Pieterse, C. M. J., Schaller, A., Mauch-Mani, B., and Conrath, U. 2006. Signaling in plant resistance responses: divergence and cross-talk of defense pathways. Pages 166-196 in: Multigenic and induced systemic resistance in plants. Tuzun, S., and Bent, E., eds. Springer Press, Boston, MA, U.S.A.

Ren, W., Sang, C., Shi, D., Song, X., Zhou, M., and Chen, C. 2018. Ubiquitin-like activating enzymes BcAtg3 and BcAtg7 participate in development and pathogenesis of Botrytis cinerea. Curr. Genet. 64: 919-930.

Robson, G. D., Kuhn, P. J., and Trinci, A. P. J. 1989a. Effect of validamycin A on the inositol content and branching of Rhizoctonia cerealis and other fungi. J. Gen. Microbiol. 135:739-750.

Robson, G. D., Kuhn, P. J., and Trinci, A. P. J. 1989b. Effect of validamycin A on the production of cellulase, xylanase and polygalacturonase by Rhizoctonia solani. J. Gen. Microbiol. 135:2709-2715.

Saijo, Y., and Loo, E. P. I. 2020. Plant immunity in signal integration between biotic and abiotic stress responses. New Phytol. 225:87-104.

Shen, Y. 1981. Development of agricultural antibiotic jinggangmycin. Chinese J. Antibiot. 6:58-62.

Shi, Y., Sun, H., Wang, X., Jin, W., Chen, Q., Yuan, Z., and Yu, H. 2019. Physiological and transcriptomic analyses reveal the molecular networks of responses induced by exogenous trehalose in plant. PLoS One 14 e0217204.

Shigemoto, R., Okuno, T., and Matsuura, K. 1989. Effect of validamycin A on the activity of trehalase of Rhizoctonia solani and several sclerotial fungi. Jpn. J. Phytopathol. 55:238-241.

Shigemoto, R., Okuno, T., and Matsuura, K. 1992. Effects of validamycin A on the growth of and trehalose content in mycelia of Rhizoctonia solani incubated in a medium containing several sugars as the sole carbon source. Ann.Phytopath. Soc.Jpn. 58:685-690.

Shimono, M., Sugano, S., Nakayama, A., Jiang, C. J., Ono, K., Toki, S., and Takatsuji, H. 2007. Rice WRKY45 plays a crucial role in benzothiadiazole-inducible blast resistance. Plant Cell 19:2064-2076.

Shoresh, M., Yedidia, I., and Chet, I. 2005. Involvement of jasmonic acid/ethylene signaling pathway in the systemic resistance induced in cucumber by Trichoderma asperellum T203. Phytopathology 95 76-84.

Tayeh, C., Randoux, B., Vincent, D., Bourdon, N., and Reignault, P. 2014. Exogenous trehalose induces defenses in wheat before and during a biotic stress caused by powdery mildew. Phytopathology 104:293-305

Trinci, A. P. J. 1985. Effect of validamycin A and L-sorbose on the growth and morphology of Rhizoctonia cerealis and Rhizoctonia solani. Exp. Mycol. 9:20-27.

Vidhyasekaran, P. 2015. Signaling and Communication in Plants: Salicylic acid signaling in plant innate immunity. Pages 90-96 in: Plant Hormone Signaling Systems in Plant Innate Immunity. F. Baluska, ed. Springer Press, Dordrecht.

Xu, Y., Charles, M. T., Luo, Z., Mimee, B., Tong, Z., Véronneau, P. Y., Roussel, D., and Rolland, D. 2019. Ultraviolet-C priming of strawberry leaves against subsequent Mycosphaerella fragariae infection involves the action of reactive oxygen species, plant hormones, and terpenes. Plant Cell Environ. 42:815-831.

Yang, L., Zhao, X., Zhu, H., Paul, M., Zu, Y., and Tang, Z. 2014. Exogenous trehalose largely alleviates ionic unbalance, ROS burst, and PCD occurrence induced by high salinity in Arabidopsis seedlings. Front. Plant Sci. 5:570.

Yu, W., Zhao, R., Wang, L., Zhang, S., Li, R., Sheng, J., and Shen, L. 2019. $\mathrm{ABA}$ signaling rather than ABA metabolism is involved in trehaloseinduced drought tolerance in tomato plants. Planta 250:643-655.

Zhang, S., Guo, Y., Tang, W. and Niu, C. 2001. Studies on the toxicity and mechanism of jinggangmycin A on Rhizoctonia solani AG-1 IA Chinese J. Pestic. Sci. 4:31-37

Zhang, S., Yang, X., Sun, M., Sun, F., Deng, S., and Dong, H. 2009. Riboflavin-induced priming for pathogen defense in Arabidopsis thaliana. J. Integr. Plant Biol. 51:167-174.

Zhou, M., Duan, Y., and Wang, J. 2018. Metconazole-containing pesticide composition for preventing and controlling fusarium head blight and application thereof. United States Patent No. 9,949,479B2. 